\title{
On motion analysis and elastic response of floating offshore wind turbines
}

\author{
Azin Lamei ${ }^{1} \cdot$ Masoud Hayatdavoodi $^{1}$ (D)
}

Received: 20 April 2019 / Accepted: 26 December 2019 / Published online: 12 February 2020

(c) The Author(s) 2020

\begin{abstract}
Wind energy industry is expanded to offshore and deep water sites, primarily due to the stronger and more consistent wind fields. Floating offshore wind turbine (FOWT) concepts involve new engineering and scientific challenges. A combination of waves, current, and wind loads impact the structures. Often under extreme cases, and sometimes in operational conditions, magnitudes of these loads are comparable with each other. The loads and responses may be large, and simultaneous consideration of the combined environmental loads on the response of the structure is essential. Moreover, FOWTs are often large structures and the load frequencies are comparable to the structural frequencies. This requires a fluid-structure-fluid elastic analysis which adds to the complexity of the problem. Here, we present a critical review of the existing approaches that are used to (i) estimate the hydrodynamic and aerodynamic loads on FOWTs, and (ii) to determine the structures' motion and elastic responses due to the combined loads. Particular attention is given to the coupling of the loads and responses, assumptions made under each of the existing solution approaches, their limitations, and restrictions, where possible, suggestions are provided on areas where further studies are required.
\end{abstract}

Keywords Offshore wind energy · Floating structures · Wave and wind loads · Loads and response coupling · Elasticity

\section{Introduction}

Concerns about the environmental pollutants and significant increase in energy demands have led to an urge for exploring renewable energies. Wind energy, among the alternatives of fossil fuels, is the most rapidly growing source of energy and one of the most mature renewable energy supplies. Wind industry has been developed significantly to harvest the wind power through mainly onshore sites, see Aubault and Roddier (2013). As reported by World Energy Council (2016), world wind energy capacity doubles about every three and a half years since 1990. Interest for expanding the wind energy production and the limitations of onshore lands for wind farms have led into the development of offshore wind turbine industry. In the UK, for example, offshore wind energy production has exceeded onshore wind production in the second quarter of year 2019, see Waters and Spry (2019).

Masoud Hayatdavoodi

mhayatdavoodi@dundee.ac.uk

1 Civil Engineering Department, School of Science and Engineering, University of Dundee, Dundee DD1 4HN, UK
The total global installed offshore capacity by year 2018 was $18.8 \mathrm{GW}$, reported by Global Wind Energy Council (2018). In 2017, the first floating wind farm was commissioned in Scotland, UK, in a water depth of $96-110 \mathrm{~m}$. Among the European countries, the UK is the leading offshore wind producer owning $36 \%$ share of the offshore installed capacity in the world, see Global Wind Energy Council (2018).

One of the first developments of offshore wind was the Vindeby project in early 1990s in Denmark (Aubault and Roddier 2013). The wind turbines were installed nearshore in shallow waters and fixed to the seabed. Such wind turbines, deployed in nearshore, are confined to water depths typically less than $50 \mathrm{~m}$ using fixed foundations, see Goupee et al. (2014). Farther from the shore, the wind is more consistent and its average speed is higher than onshore and nearshore sites. Moreover, in many places, water depth changes rapidly, leaving limited zones for offshore wind resources in shallow waters. Thus, the industry is exploring the Floating Offshore Wind Turbine (FOWT) concepts.

Figure 1 shows the variation of average wind speed at $80 \mathrm{~m}$ elevation (on land) around the world. The seasonal variation of the wind speed over the oceans at $10 \mathrm{~m}$ above the sea level is shown in Fig. 2. The two figures refer to the wind speed at 




Fig. 1 Mean wind speed at $80 \mathrm{~m}$ elevation on land [Reprinted with permission from VAISALA (2015)]
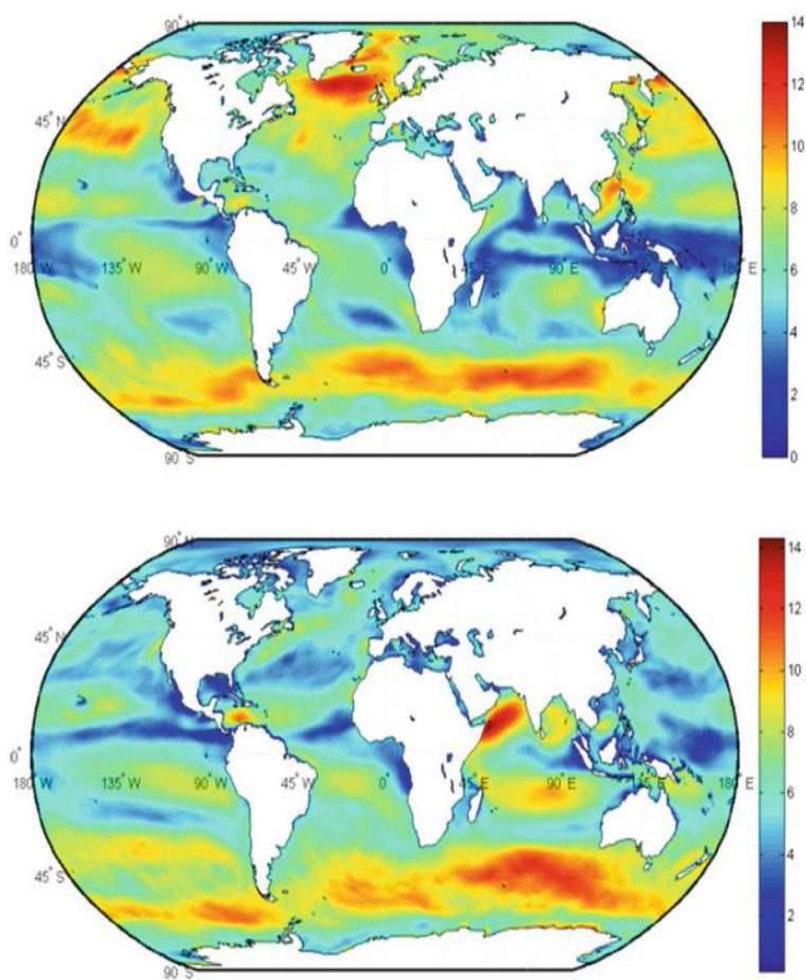

Fig. 2 Mean December (top) and July (bottom) wind speed (m/s) over the oceans to $10 \mathrm{~m}$ elevation above the sea level offshore in 2014 [Reprinted with permission from Craddon et al. (2016)]

slightly different elevations onshore and offshore. However, a comparison between these two indicates the strength of wind resources in open oceans. With a comparison between Figs. 1 and 2, it can be seen that the offshore winds reach to higher speeds than wind speed at onshore lands. As shown in Fig. 1, the maximum average wind speed onshore is above $9 \mathrm{~m} / \mathrm{s}$ in limited areas, whereas in offshore sites (Fig. 2), the wind speed reaches $14 \mathrm{~m} / \mathrm{s}$ in larger sites.
Several full-scale FOWT concepts are proposed, developed, and tested. The Hywind project (Keseric 2014), a (Single point anchor reservoir) SPAR buoy installed in Norway, is the world's first grid-connected FOWT. The structure was installed off the Norwegian coast in water depths of approximately $200 \mathrm{~m}$. Following similar concept, a pilot park with capacity of $30 \mathrm{MW}$ is installed in Scotland in 2017. Goto Island project in Japan was developed supporting the wind turbine on an SPAR structure with varying diameter, see Utsunomiya et al. (2015). In WindFloat project (Cermelli et al. 2009), the wind turbine is mounted on a triangular semi-submersible floater with three columns. With small operational draft, transition of WindFloat structure from harbour is relatively easier.

Some similarities exist between floating structures of the oil and gas (O and $\mathrm{G})$ industry and FOWTs, allowing for partial transfer of the technology, see, e.g., Musial et al. (2004), Wang et al. (2010), Goupee et al. (2014). However, size of the platform and the aerodynamic loads on the wind turbine are major differences, which have significant effect on the overall responses. Installing the wind turbine on top of the platform adds a remarkable weight to the structure. Hence, design of the ballast and the mooring lines of a FOWT require significant attention, see Butterfield et al. (2005). These introduce a unique challenge to design and analysis of FOWTs that should be properly addressed.

An understanding of the motion and structural response of a floating wind turbine requires an estimation of the wind load, wave load, current load, mooring line forces, and the coupling between them. Analysing the dynamics and elastic response of the structure, including the rotor, tower, and the floater is a significant challenge for the state-of-the-art.

FOWTs are complex systems and involve various considerations. The focus of this review is on the approaches developed to analyse FOWTs. Table 1 presents a list of relevant review studies covering different aspects of floating offshore wind turbines. Here, we confine our attention to theoretical and experimental approaches developed to analyse the response of FOWTs to a combination of waves, wind, and current loads.

In Sect. 2, typical FOWT concepts are reviewed with an emphasis on their unique characteristics. The environmental loads on FOWTs and their responses are discussed in Sect. 3. This is followed by a review of the existing approaches to determine the loads on floating wind turbines in Sect. 4. The coupling tools developed to determine the responses to combined loads are discussed in Sect. 5. Assumptions and limitations of the existing analysis approaches are critically reviewed and suggestions for further studies are presented. The challenges of experimental studies of FOWTs are discussed and remarkable model tests are reviewed in Sect. 6. 
Table 1 A list of published review studies on various aspects of FOWTs

\begin{tabular}{ll}
\hline Topic & References \\
\hline Offshore wind energy resources & World Energy Council (2016) \\
& Craddon et al. (2016), Wind Europe (2018) \\
& Global Wind Energy Council (2018) \\
FOWT platform concepts & Musial et al. (2004), Butterfield et al. (2005) \\
& Wang et al. (2010), Thiagarajan and Dagher (2014) \\
& Uzunoglu et al. (2016) \\
Modelling tools for FOWTs & Cordle and Jonkman (2011), Matha et al. (2011) \\
& Matha et al. (2016) \\
Aerodynamics and aeroelasticity analysis & Hansen et al. (2006), Leishman (2002) \\
of horizontal axis wind turbines & Zhang and Huang (2011), Sørensen (2011) \\
& Wang et al. (2016) \\
Hydroelasticity of floating offshore & Chen et al. (2006), Lamas-Pardo et al. (2015) \\
structures (any floating structure) & Jiao et al. (2017) \\
\hline
\end{tabular}

\section{Floating structures of offshore wind turbines}

Typical design characteristics of FOWT structures are presented in this section. The floating concepts used for FOWTs show some similarities to the floating platforms that have been used by the $\mathrm{O}$ and $\mathrm{G}$ industry, see Butterfield et al. (2005). However, there are some remarkable differences between these substructures that must be considered at the design and analysis stages. The main difference lies in the total load on the floater. The additional aerodynamic load affects the responses of the structure significantly. For a costeffective design of FOWTs, it is necessary to optimise the complete system including the wind turbine, platform, and the mooring layout.

Based on the number of wind turbines on the platform, the substructures designed for FOWTs are classified into two main groups, namely single-unit floaters and multi-unit floaters, see Wang et al. (2010).

Single-unit FOWTs can be classified into three categories based on how they achieve the static stability and withstand the wind turbine overturning thrust load, namely buoyancystabilised, mooring-stabilised, and ballast-stabilised platforms, see Uzunoglu et al. (2016). These are discussed in the following subsections.

\subsection{Buoyancy-stabilised platforms}

Semi-submersible structures achieve their stability due to a balance between weight and buoyancy of the floater at operational conditions. The key characteristics of semisubmersibles is the small draft and large water plane area. Semi-submersibles consist of pontoons and columns provid- ing the buoyancy of the structure, where typically the wind turbine is located on one of the columns, see Wang et al. (2010). To mitigate the heave motion of the platform, water entrapment or heaving plates with large radii may be added at the end of the columns, see, e.g., Henderson et al. (2016). In semi-submersibles, the heave, pitch, and roll motions are mainly restricted by the hydrostatic restoring forces, while catenary mooring lines are used to restrict the surge, sway, and yaw motions. A review of semi-submersible foundations is given in Liu et al. (2016).

WindFloat (Cermelli et al. 2009), as shown in Fig. 3, and V-shape semi-submersible and four column semi-submersible (Carbon Trust 2015) in Japan are examples of semi-submersible platforms with three columns. DeepCwind triangular platform (Robertson et al. 2013) consists of three columns at the corners, and one additional column in the centre where the wind tower is installed. Within the same category of floaters, a concept design by Fukushima Shimpuu is a V-shape semisubmersible made of three columns and two pontoons, where the turbine is installed on the middle column, see Karimirad and Michailides (2015).

\subsection{Mooring-stabilised platforms}

Stability of tensioned leg platforms (TLP) or tensioned buoyant platforms (TBP) is achieved by mooring lines. Described by Henderson et al. (2016), a typical FOWT TLP concept compromises of a central slender buoy connected to a number of legs. The floater is connected to the seabed via tensioned tendons attached to the legs. The tendons restrict the motion of the floater in roll, pitch, and heave motions. Failure of a mooring line of a TLP may result in the failure of the entire system, since the floater cannot keep the structure afloat Nihei 


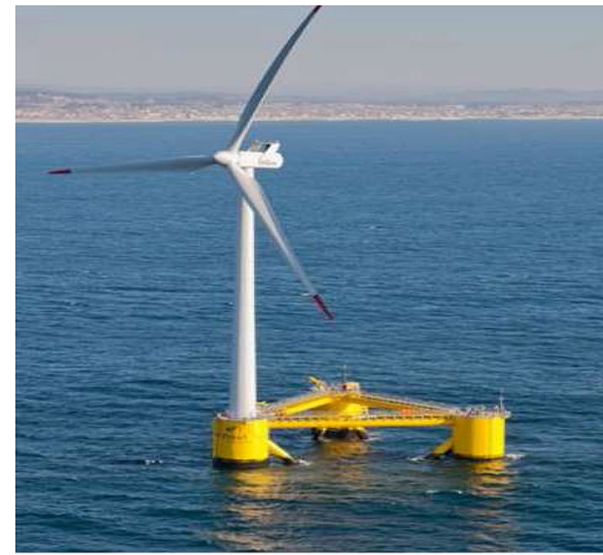

(a)

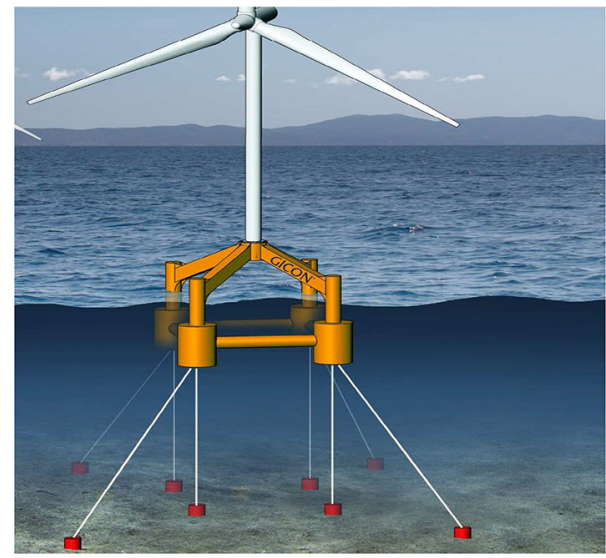

(b)

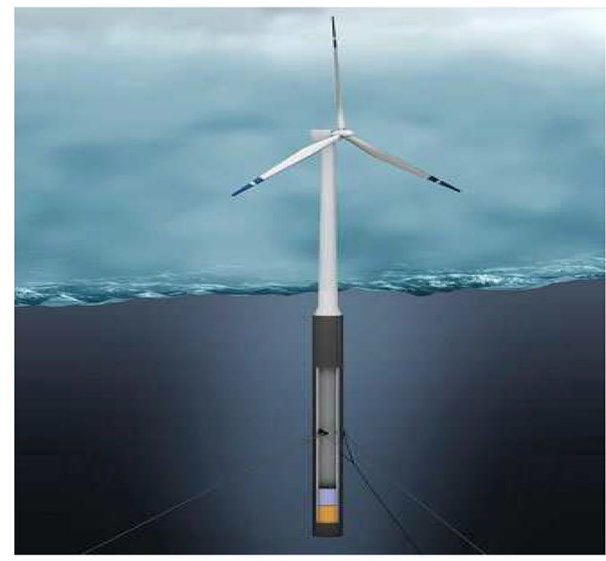

(c)

Fig. 3 a A buoyancy-stabilised platform, WindFloat project, b a mooring-stabilised platform, TLP, Gicon project, and c a ballaststabilised platform, HyWind project [Reprinted with permission from Carbon Trust (2015)]

et al. (2011). Thus, TLPs are provided with extra station keeping tendons to support the structure in cases of a line loss. TBPs, in contrast to TLPs, are provided by two layers of mooring lines inclined relative to the seabed using gravity anchors. With these mooring lines, the structure is a stiff floater that responds only to the flexural deflections of the mooring tensioned lines and the tower, see Sclavounos et al. (2010). Installation of a TLP platform requires specialised vessels, which increases the costs. Moreover, vertical-load anchors are used for the mooring system of a TLP, resulting in relatively more expensive mooring system.

In a review by Adam et al. (2014), several concept projects of TLP/TLB floaters for FOWT are introduced, which are at the design stage, e.g., Iberdrolas TLP and PelaStar projects. Moreover, in GICON-TLP concept (Fig. 3), a combination of vertical and angled mooring lines are applied to further restrict the motions of the structure.

\subsection{Ballast-stabilised platforms}

SPAR platforms achieve their stability by the relative location of the centre of gravity and the centre of buoyancy, see Uzunoglu et al. (2016). SPARs are typically used in deep waters. The ballast water at the bottom of the cylinder restricts the pitch and roll rotational motions. The mooring lines are used to keep the SPAR in place and to restrict the yaw, surge, and sway motions. Since the water plane area of the cylinder is small, the restoring forces are not large enough to limit the heave motion, see Henderson et al. (2016). However, SPARs typically have large drafts, and hence, there is negligible vertical forces acting on the structure, and therefore, their heave motion is small. Pitch motion of an SPAR is an important design factor. Large pitch motions result in instantaneous change of relative wind direction on the wind turbine rotor. This may cause challenges to the gyroscopic stability of the hull, see Goupee et al. (2014). Thus, the use of the pitch control system is inevitable for an SPAR wind turbine. Vortex-induced vibrations (VIV), mainly due to wave and current interactions with the structure, create another technical challenge to design SPARs. In these cases, the structure experiences unsteady loading due to flow separation and formation of the vortices and the wake region. There are several approaches to reduce VIV, see, e.g., Rashidi et al. (2016).

Discussed by Uzunoglu et al. (2016), SPARs are relatively easy to build (compared to TLPs and semi-submersibles), and are known for lower dynamic response per displacement. SPARs were successfully tested by HyWind (Keseric 2014) demo project in Norwegian coasts, Fig. 3. There are other similar concepts studied in the US and Japan exploring possible modifications of SPAR platforms to optimise its stability, size, and cost for FOWTs, see, e.g., Bento and Fontes (2019).

\subsection{Multi-unit floater concept}

Multi-unit concepts are introduced with the main objective of reducing the overall cost of the energy production. For a multi-unit floater, single grid connection can be used. The rotor wake effect of the turbines mounted on the same floater 
should be studied carefully. In this case, the size of the floater is typically determined to minimise the wake effect of the leading turbines on the trailing turbines and improve the power output. The multi-unit platforms are still at the concept stage. Further analysis are required to prove their economic benefits.

Hexicon (Carbon Trust 2015) accommodates two wind turbines installed on a large semi-submersible platform, see Fig. 4. Ishihara et al. (2007) proposed a semi-submersible

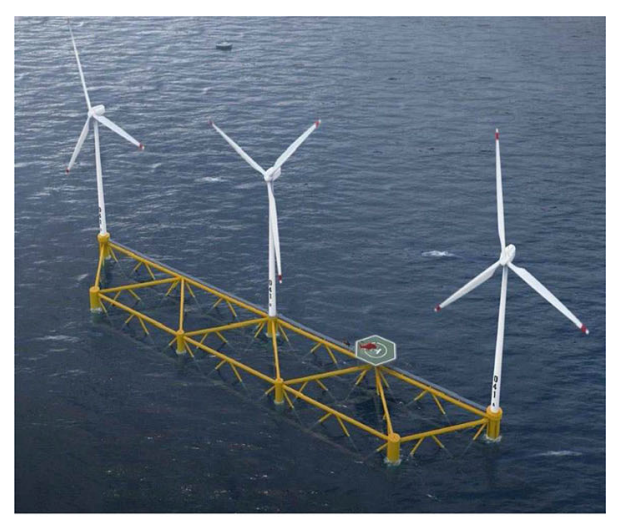

(a)

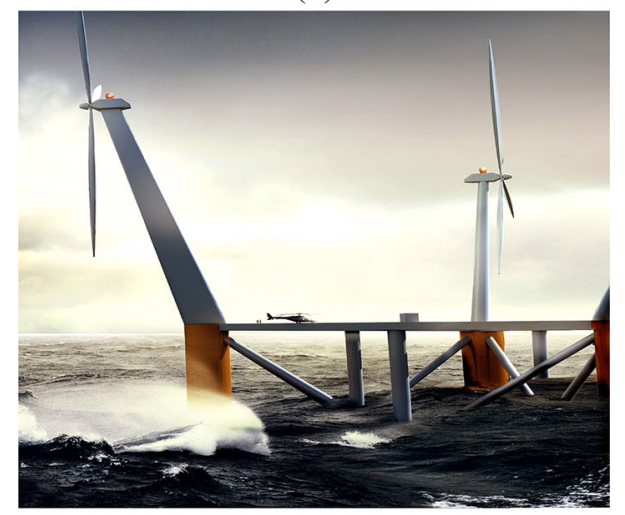

(b)

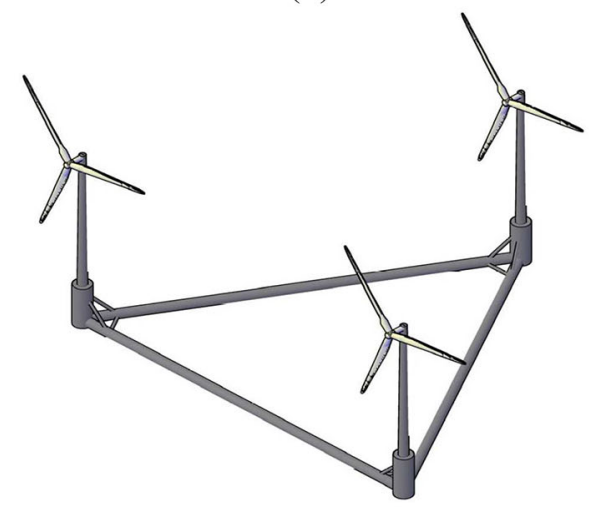

(c)

Fig. 4 Multi-unit floater concepts, a Hexicon project, b WindSea project [Reprinted with permission from Carbon Trust (2015)], and c wind-tracing multi-unit platform, [Reprinted with permission from Lamei et al. (2019)] floater hosting three wind turbines. The structure consists of three base floaters for the turbines and one central floater to connect the girders together. In this design, to reduce the wave loads, the restoring stiffness is suppressed which consequently increases the natural periods of the structure.

Yet, another concept has been suggested by Wong (2015), namely a wind-tracing platform, as shown in Fig.4c. The mooring lines of the floater are designed, such that the body can rotate to face the dominant wind direction. The floater is triangular, supporting three wind turbines. A preliminary hydroelastic analysis of the wind-tracing floater is given in Lamei et al. (2019) and concept design of the structure is discussed in Li et al. (2019). Similarly, WindSea (Carbon Trust 2015) is a wind-tracing concept where the mooring lines are connected by a turret bearing to allow the platform to rotate and face the incoming wind, see Fig. $4 \mathrm{~b}$. The platform is a semi-submersible floater with three columns for each turbine. Inclined towers are used to reduce the interaction between rotor blades.

\section{Wind, wave, and current loads}

Dynamics of an FOWT is governed by the environmental loads which includes wind, waves, and current, and in some places ice loads. An appropriate analysis of an FOWT must account for all the sources of the loads on the floating structure and the wind turbine. For reviews on ice loads on floating structures (not discussed in this paper), see, for example, Tuhkuri and Polojärvi (2018) and Sayeed et al. (2017).

In this section, we review the existing approaches in determining the wind, waves and current loads on FOWTs. Assumptions made in developing each approach and the associated limitations are highlighted.

\subsection{Aerodynamic loads}

Wind has a random nature with fluctuations in its speed and direction at different scales in time and space. Wind can be defined as the sum of long-term wind statistics and shortterm, small-scale fluctuations. The long-term statistic give the distribution of the average wind speed. This is usually applied for load analysis, see Vorpahl et al. (2013). Due to the large height of wind turbines, the wind shear profile varies the load distribution on wind turbines. Moreover, the extreme wind speeds and gusts are of great importance for the load simulations and design of wind turbines.

Wind passes through the rotor and the turbine partially extracts the kinetic energy to generate electricity. The wake behind the wind turbine is characterised by decreased flow velocity, increased turbulence, and pressure drop. Pressure increases gradually downstream of the rotor approaching atmospheric pressure at sufficiently far distance away. Dif- 
ferent flow circulations along the blade result in formation of vortex sheets. In a short distance downstream, vortices shed from trailing edge of the blades and roll up to form tip vortices in helical path, see, e.g., Manwell et al. (2002), Hansen (2007), and Sørensen (2011). Formation of the wake region behind the rotors results in velocity deficit and reduction of power outputs in rear wind turbines in an array configuration. It also results in unsteady loading on the downstream rotors. In developing wind farms, modelling the wake and array effects are essential to optimise the power output, see, e.g., Göçmen et al. (2016) for more information about modelling the wakes.

To compute the thrust force and the power output of a wind turbine, the unsteady flow distribution around the blades should be determined. The theoretical approaches used for this purpose are discussed in the following subsections. These methods are explained starting from those that include the least number of assumptions (high-fidelity methods), followed by those that require higher number of assumptions (mid-fidelity methods) and continued by simplified methods (low-fidelity methods). Reviews of the methods used to study aerodynamic loads on wind turbines can be found in, e.g., Leishman (2002) and Hansen et al. (2006).

\subsubsection{High-fidelity methods}

Computational fluid dynamic (CFD) models solve the Navier-Stokes (NS) equations to study the air flow field on the blades and behind the rotor. In Eulerian CFD methods, the partial differential equations are solved computationally by discretizing the domain both in time and space. The most common methods are finite-difference (FD), finite-volume $(\mathrm{FV})$, and finite-element (FE) methods. Modelling the turbulence effects near the solid boundaries and in the wake region has remained a challenging problem to the scientific and engineering community. Various approaches have been proposed and used to study turbulence effects in flow fields.

A relatively accurate approach to simulate the turbulent flow is to solve the NS equations with numerical discretization of the flow field, considering all the motions of the flow. This approach, known as the direct numerical simulation (DNS), requires very fine mesh and is computationally very expensive, see, e.g., Moin and Mahesh (1998) for more information. Hence, it is very difficult to use DNS for flow simulation around FOWTs. DNS, due to the extreme computational cost, has not been used to analyse FOWTs, and it is unlikely that it would be used in the near future.

An approximation can be made about the turbulence effects and only consider the large-scale motions of the flow and hence reducing the computational cost. This is known as large eddy simulation (LES) approach. In this method, large eddies are directly solved, whereas small eddies are modelled by subgridscale models, see, e.g., Bose and Park (2018), Wu



Fig. 5 Wake structure with different turbulence models for tip speed ratio (TPS) 3 [Reprinted with permission from Mittal et al. (2016)]

and Port e Agel (2015), and Sedaghatizadeh et al. (2018) for LES simulations of wind turbine aerodynamics.

The Reynolds-Averaged Navier-Stokes (RANS) equations is another approach in approximating the turbulence dynamics. In this approach, the NS equations are decomposed into time-averaged, fluctuating components and nonlinear stress terms. To capture the turbulence, several models have been proposed, including k- $\epsilon$, k- $\omega$ SST, SpalartAllmaras, and the Baldwin-Barth models [see Hansen et al. (2006) and Thé and Yu (2017)]. Figure 5 demonstrates the wake structure behind a wind turbine by use of different turbulence models. See, e.g., Tran et al. (2014) for aerodynamic analysis of wind turbines using the RANS method.

A combination of both RANS model for the attached flow and LES for the deeply separated region is also proposed by Spalart (2009), known as the detached eddy simulation (DES), see, e.g., Mittal et al. (2016). In this approach, RANS method is applied to the regions near the boundary layers with small turbulent length scales, whereas the large turbulent length scales are modelled by LES method, see, e.g., Li et al. (2012), Zhang et al. (2019), and Fang et al. (2020) among others for CFD analysis of FOWTs by use of DES. CFD simulations provide a more detailed flow field around the wind rotor and in the wake region than any other approaches, see Vermeer et al. (2003). This, however, is achieved with highest computational cost than any other approach.

\subsubsection{Mid-fidelity methods}

Actuator Disc Model is a mid-fidelity method to determine aerodynamic loads on wind turbines. In the Actuator Disc Model (ADM) developed by Mikkelsen (2003), the rotor is defined as a permeable disc that allows the airflow to pass through, see Hansen et al. (2006). In the ADM method, the wind-induced tangential and normal forces on the blades are distributed on the circular disc. The classical actuator disc model is based on conservation of mass, momentum, and energy. This method can be used to solve NS or Euler's 
equations, see Sørensen (2011). Compared to CFD methods, ADM does not require a detailed mesh of the blade geometry or iterative solution of the equations, and hence, computations are significantly faster. Actuator Line Model (ALM) is a modified version of ADM. In ALM method, the geometry of the blade is simplified by radial lines representing the load distribution on the rotor, see Sørensen et al. (2015).

In ADM and ALM approaches, lift and drag coefficients are used to determine the rotational effect of the blades. These coefficients depend on the angle of attack of the blades, and are usually obtained through wind tunnel measurements, or by performing CFD computations of wind interaction with a turbine rotor.

One can assume that air is inviscid and incompressible, and that wind is an irrotational flow, and hence use velocity potential to describe the three-dimensional flow around a rotor. In vortex lattice method, based on the ideal fluid flow assumption, discrete vortex sheets are distributed over the blade geometry to model the lift. The empirical lift and drag coefficients are used in this method. In boundary-element method, also based on the ideal fluid flow assumption, the blade geometry is recreated by distributing sources and sinks and the equations are used by the Green theorem, see Morino (1993). In both three-dimensional models, the wake flow is approximated by adding vortex elements which are distributed on points or lines and shed from the trailing edge of the blades. The trajectory of the vortex elements may be prescribed or left as an unknown to be determined by the calculations. Prescribed vortex method is used when the flow is steady, see, e.g., Melo et al. (2018). The free wake solution is applied to unsteady flows and requires substantially higher computational times, see, e.g., Zhu et al. (2002) and Jeon et al. (2014). Main limitations of these methods are due to the numerical stability of vortex models. Viscosity, which is not considered directly, plays an important role in the flow separation, formation of the wake region, and stall effects. Sebastian and Lackner (2012a, b), Qiu et al. (2014), Marten et al. (2015) and Rodriguez and Jaworski (2019), among others, have performed aerodynamic analysis of FOWTs using vortex methods. Empirical relations may be used, along with these approaches, to study complex air flows, see, e.g., Kim et al. (2010), Abedi et al. (2017), Lee and Lee (2019).

\subsubsection{Low-fidelity methods}

The wind loads on the blades can be approximated by the Blade Element Momentum method (BEM) suggested first by Glauert (1963). In BEM method, the flow is twodimensional, divided into annular control volumes, and conservation of momentum and energy equation are applied to each cell. Lift and drag coefficients are defined and used in this method to determine the air-induced loads an each cell. The coefficients depend on the shape of the cells and the airflow velocity, see, for instance, Thé and Yu (2017). Prandtl's tip loss correction is used to capture the formation of the vortices from the tip, which is a three-dimensional phenomenon. This approach is not suitable for stall effects due to the unsteady conditions and three-dimensional (3D) flow. Rotation of the rotor results in the formation of the Coriolis and centrifugal forces, which are remarkable. These are not considered in a two-dimensional (2D) presentation of the blade, see Hansen et al. (2006) and Syed Ahmed Kabir and $\mathrm{Ng}$ (2017) for more details. It is possible to obtain the 3D airfoil data by CFD approaches for use by the BEM, see, for instance, Du and Selig (1998), Du and Selig (2000), and Guma et al. (2018). Another limitation of BEM method is that the effect of the adjacent elements is neglected.

To account for viscous effects and inflow and tangential velocity variations in BEM, some empirical corrections are developed, for instance the Glauert correction, skewed wake corrections, and unsteady airfoil aerodynamics, see Matha et al. (2011), Leishman (2002) and Vorpahl et al. (2013) for more details. BEM is relatively simple and fast to run, and hence it is commonly used by the industry.

Due to the motion of the structure, the rotor and tower of FOWTs are exposed to more complex aerodynamic loads when compared to nearshore (fixed) and onshore wind turbines. The motion of the substructure of floating wind turbines results in unsteady inflow, see Sebastian and Lackner (2010). In FOWTs, additional relative wind motions are introduced due to the translational and rotational motions of the structure. Thus, the numerical aerodynamic tools discussed so far should be modified for applications related to the FOWTs.

\subsection{Hydrodynamic loads}

In FOWTs, aerodynamic loads on the wind turbine and hydrodynamic loads on the floating structure can be comparable in their magnitude and collectively determine the motion of the structure. For instance, for the multi-unit wind-tracing platform, the total horizontal force for headseas regular waves is computed by linear wave diffraction theory, as shown in Fig. 6 (for water depth $h=-200 \mathrm{~m}$ and wave height $H=1 \mathrm{~m}$ ). For co-directional wind flow to the towers, the total aerodynamic loading on the three rotors (standard $5 \mathrm{MW}$ NREL turbine) reaches up to $3 \mathrm{MN}$ at rated wind speed of $U_{W}=11.4 \mathrm{~m} / \mathrm{s}$, see Lamei et al. (2019) and Li et al. (2019) for more details about this structure and the calculation.

The theoretical tools developed for hydrodynamic loads on offshore wind turbine substructures closely follow the existing approaches used by the $\mathrm{O}$ and $\mathrm{G}$ industry and Naval Architecture. These theoretical approaches either explicitly solve the appropriate governing equations or offer empirical relations to estimate the forces and the motion of the structure, see Matha et al. (2016). A review of these approaches 


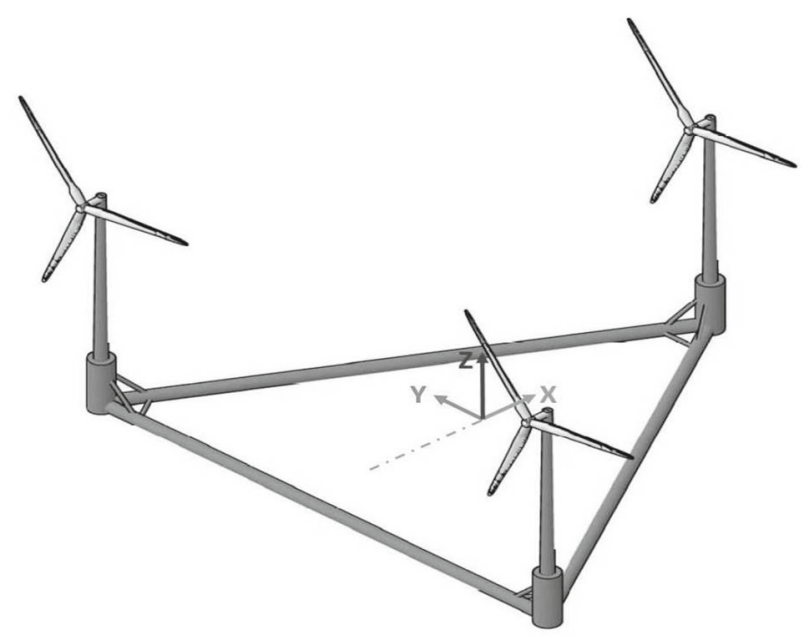

(a)

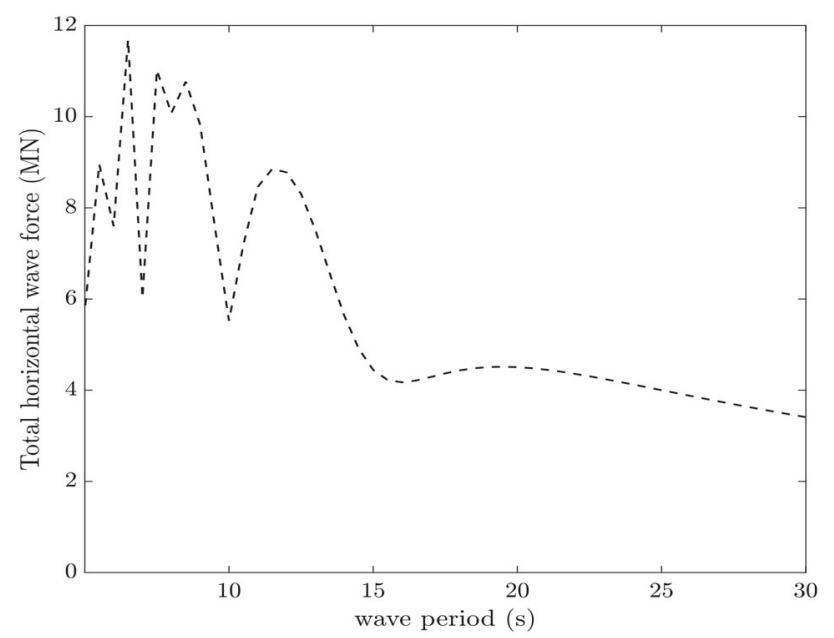

(b)

Fig. 6 a The triangular, wind-tracing multi-unit platform. b Total horizontal wave force on this platform

is given below, focusing on their application in design and analysis of FOWTs. More details about hydrodynamic loads on floating bodies can be found in, e.g., Faltinsen (1990) and Newman (1978).

\subsubsection{High-fidelity methods}

With CFD computational tools, the instantaneous pressure distribution and the wave forces on the floater are determined. For floating bodies, finite-volume (FV) method is often used to solve the governing equations due to its relative simplicity and possibility to use with complex geometries, see, e.g., Kleefsman et al. (2005), Panahi et al. (2006), Benitz et al. (2014) among others. Discussed in the previous section, there are several approaches to approximate the turbulence effect, for instance RANS and LES simulation. Moving boundaries (in the case of the floating bodies) create further computational challenge to generate the mesh. Specialised techniques such as Immersed Boundary Method (IBM) are used for these cases, see, e.g., Viré et al. (2013) and Bihs et al. (2017).

Another method to study the fluid-structure interaction problem is by use of the Lagrangian approaches. Smoothed Particle Hydrodynamics (SPH) is a mesh-less Lagrangian approach to solve the NS equations, see, e.g., Gingold and Monaghan (1977). In this approach, the physical properties of the fluid are stored at the centre of series of particles. Particles, representing the fluid volume, move according to the NS equations in Lagrangian form, see, e.g., Liu and Liu (2010), Gomez-Gesteira et al. (2010) for more details. Shadloo et al. (2016) gives a review about this method and its shortcomings. See for instance Leble and Barakos $(2016 a, b)$ for SPH studies on FOWTs. In general, the convergence, numerical stability, and boundary conditions are of the main challenges in SPH method. SPH approach is advantageous in modelling multi-physics flows and associated transport phenomena due to its capabilities of handling complex boundary evolution, for instance, in the case of green water effects.

The Lattice Boltzmann method based on the kinetic theory is yet another approach that is used to compute continuum flow properties based on particle interactions. In this mesoscopic method, propagation and collision of particles in time and space are determined by use of the kinetic theory and prescribed collision schemes. A review on this approach can be found in Aidun and Clausen (2010). Bogner and Rüde (2013) solved the interaction of water waves with floating bodies using the Lattice Boltzmann method. To the authors' knowledge, this method has not been applied to FOWTs.

\subsubsection{Mid-fidelity methods}

Yet, another approach in determining nonlinear wave loads on structures is by use of nonlinear, water wave theories, such as the Green-Naghdi (GN) equations. The GN equations, originally developed by Green and Naghdi (1974, 1976a, b), are nonlinear, partial differential equations that describe unsteady motion of homogeneous, incompressible, inviscid fluids. Irrotationality of the flow is not required, although this assumption can be made. The nonlinear boundary conditions, conservation of mass, and integrated conservation of momentum and energy are satisfied exactly by the GN equations. The GN equations are classified based on the assumption made in describing the distribution of the velocity field over the water column. In Level I GN equations, for example, the vertical velocity varies linearly from the seafloor to the free surface. Hence, the Level I GN equations are mostly applicable to the propagation of long waves in shallow water, see, e.g., Ertekin et al. (1986). Higher level GN equations, applicable to deep waters, are obtained by considering exponential or higher order polynomial function for the velocity distribution over 
the water column, see Zhao et al. (2014a, b, 2015), Webster and Zhao (2018), among others. The Level I GN equations have been used to study various fluid-structure interaction problems including the nonlinear wave loads on horizontal decks [by, e.g., Hayatdavoodi and Ertekin (2015a, b), Hayatdavoodi et al. (2019)] and wave impact on vertical cylinders (Neill et al. 2018, Hayatdavoodi et al. 2018, among others).

Another mid-fidelity approach is the fluid impulse theory (FIT), which addresses the gap between time-domain Morison's equation for slender bodies and the frequency-domain approaches. It allows for the evaluation of higher order nonlinear effects by use of compact force expressions. Chan et al. (2015) evaluated this method for nonlinear sea-state loads on a TLP substructure of a wind turbine.

\subsubsection{Low-fidelity methods}

For most of the Ocean Engineering problems, the viscous effects are important in formation of the boundary layer and the wake region and in some specific cases such as wave breaking. In some problems, viscous effects are negligible, and hence, the fluid is assumed inviscid. With the assumption of incompressible and inviscid fluid and irrotational flow, the flow is governed by Laplace's equation. In linear diffraction theory, the body motions are assumed small and the nonlinear wave-body interaction is ignored. Assuming small-amplitude waves, this results in a linear system of equations for the fluid-structure interaction problem. The system of equations can be solved by Boundary-Element Methods (BEM), among other approaches. The BEM solution is based on the Green theorem by distributing the unknown singularities on the boundaries of the computational domain, see, e.g., Liu et al. (2018) of recent studies on potential-flow solvers.

In some extreme cases, nonlinear effects may be important when considering loads and responses, see, e.g., Matha et al. (2011), Coulling et al. (2013a) for discussion on nonlinear hydrodynamic loads on FOWTs. By considering the nonlinear boundary conditions, Laplace's equation can be solved directly by field solvers. In the field solvers, the domain is discretized with methods such as FEM, FDM, or FVM to solve the governing equations everywhere in the domain, see, e.g., Bingham and Zhang (2007), Shao and Faltinsen (2014), Li and Fleming (1997), Wu et al. (1998), EngsigKarup et al. (2008), Ducrozet et al. (2010).

Morison's equation, given by Morison et al. (1950), is an empirical approximation of inertial loads and viscous drag as slender circular cylinder. Morison's equation is widely used to obtain a first estimate of the wave-induced loads on slender cylinders. The wave diffraction effects are not considered in this approach. Combined Morison's equation and potential-flow solvers are commonly used by practitioners for hydrodynamic analysis.
In this approach, the diffraction effect is determined by potential theory, while the viscous effect is estimated by Morison's equation, see, e.g., Ramachandran (2012), Barooni et al. (2018), Ishihara and Zhang (2019), among others.

Further discussion on application of linear diffraction theory and Morison's equation to the problem of wave interaction with FOWT can be found in, e.g., Matha et al. (2011). In summary, linear approaches are mostly applicable to relatively small platform motions.

\section{Structural responses}

At deep water sites, larger wind turbines can be deployed on floating substructure. Due to the large size and displacement of the structure and comparable load and structural frequencies, analysis of elastic responses of the blades, the tower, and the supporting floating platform are of great importance. The aerodynamic and hydrodynamic loads both contribute to elastic deformation of the structure. In the previous section, methods of determining the hydrodynamic and aerodynamic loads were discussed. A review of appropriate methods of calculating the stresses and the elastic deformation of a floating wind turbine is presented here.

\subsection{Aeroelasticity}

The elastic response of wind turbines blades and towers is a result of aerodynamic loads, elastic deflections, and inertial dynamics. Comprehensive reviews on aeroelasticity of wind turbines are provided by, for example, Hansen et al. (2006), Zhang and Huang (2011), and recently by Wang et al. (2016). Here, a summary of the methods used for structural analysis of wind turbines is presented with an emphasis on recent developments.

Wind turbine blades can bend both in flap-wise (out of rotor plane) and edgewise (in the rotor plane) directions. Moreover, the blades rotate about the pitch axis extending span-wise perpendicular to the blade root flange. The tower may experience bending moments both in longitudinal and lateral directions. Torsion of the tower may also result in yaw rotations of the nacelle and the rotor.

Blades of a wind turbine are usually modelled either using a three-dimensional (3D) FEM model with shell elements or a one-dimensional (1D) beam model with beam elements. In the former method, the blades are defined by 3D composite shell elements. The composite layer characteristics are specified span-wise. Discussed by Wang et al. (2016), this method results in detailed stress distribution on the blades and allows for coupling with CFD tools to predict the aerodynamic loads, see Yeh and Wang (2017) among others. The aeroelastic tools based on 3D FEM modelling and CFD can provide comprehensive results; however, they are computa- 
tionally expensive. To make the analysis more efficient, the 3D FEM model can be coupled with BEM, see, e.g., Liu et al. (2017a), Rafiee et al. (2016), Tezduyar et al. (2008).

For more simplified approximations (and computationally fast), one can model the blades as beam members. Two widely applied beam models are the Euler-Bernoulli beam model and the Timoshenko beam model. The EulerBernoulli beam model is subjected to extensional, torsional and bending loads where the shear deformations are neglected. The Timoshenko beam model developed for thin and short beams includes the shear deformation.

The linear Euler-Bernoulli beam model has been used frequently for the aeroelastic analysis of wind turbines, mainly due to its simplicity, see Wang et al. (2016). To discretize the beam model, three methods are suggested: Modal approach, Multi-body-dynamics method (MBD), and 1D FEM method. In modal approach, the deflection shape of the beam is given as a linear combination of mode shapes. Due to its linearity, application of this method is limited to small deflections of flexible bodies. In MBD, a number of bodies, either as rigid or flexible, are interconnected by force elements or kinetic constraints. 1D FEM method provides approximate solution for elastic analysis by considering a number of elements interconnected by nodes. Although this method requires more computational resources than multi-body-dynamics and modal approach methods, in principle, it results in more accurate and comprehensive description of the deformation of the wind turbine blades. For more details on these aeroelasticity analysis approaches, see, e.g., Yu and Kwon (2014), MacPhee and Beyene (2013), Mo et al. (2015), Lee et al. (2012).

\subsection{Hydroelasticity}

When wave frequencies are close to the eigen-frequencies of the structure and when the structural deformations are comparable with rigid body responses, it is important to consider the hydroelastic responses. For FOWTs, the transferred aerodynamic loads through the tower to the platform can result in structural deformation as well. In these cases, the structural deformation may alter the wave-structure interaction responses.

Several approaches are developed for hydroelasticity analysis of floating structures. In multi-body dynamics method, the continuous flexible structure is divided into several modules. Consequently, each section is considered as a spatial beam to derive structural deformations. The force acting at the ends of each beam is related to the displacement of the beam-end by a stiffness matrix, see, e.g., Lu et al. (2019) among others for multi-body dynamics approach. Commonly, hydrostatic responses of a floating body are determined thorough two steps. First, the floater is modelled as a Timoshenko beam model or discretized by an FEM method with specified number of modes. The natural frequencies of the structure are determined without considering the hydrostatic pressure distribution, known as the dry-mode analysis. The natural frequencies and eigenvectors (mode shapes) are then computed. Next, the fluid forces on the body are computed using frequency- or time-domain analysis based on the Green theorem. The structural deformations obtained in the first step are introduced in the second step as generalised modes to the equations of motion. A review of the approaches developed to study hydroelasticity of marine structures is given in Chen et al. (2006).

Hydroelasticity is an important aspect in analysing the response of very large floating structures (VLFS). VLFS are characterised by their elastic behaviour due to their geometrical and unprecedented length scales compared with wave length and the characteristic length. Ertekin and Kim (1999) developed the nonlinear Level I Green-Naghdi theory for a floating mat of finite length. In this study, thin plate theory was applied to analyse the hydroelasticity of the rectangular runway in shallow waters. This method was modified by Xia et al. (2008) to apply linear beam theory to model the structure. The numerical tool, LGN (Ertekin and Kim 1999), models the fluid with the Green-Naghdi equations and applies linear Kirchhoff plate model for the structural analysis. In a study by Riggs et al. (2008), a comparison of the solution of numerical simulation tools for VLFS is provided. HYDRAN [see, e.g., Wang et al. (1991); Ertekin et al. (1993); Wu et al. (1993); Riggs et al. (2007)] is a wellknown computer code for analysis of floating structures with a focus on VLFS where the fluid is modelled by 3D potential theory using the Green function and the structure is modelled by a 3D shell finite-element solver. Figure 7 shows the second vertical bending mode of a VLFS predicted by HYDRAN. Suzuki et al. (2007) and Chen et al. (2006) present a comprehensive description of the VLFS and the numerical tools developed to obtain their dynamic responses.

Borg et al. (2017) considered the hydroelastic interactions between the flexible substructures and fluid during dynamic

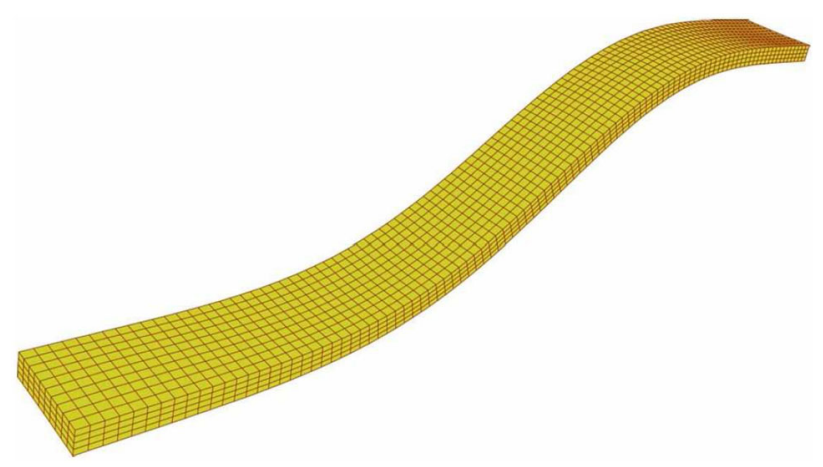

Fig. 7 Elasticity analysis of a VLFS by HYDRAN, second vertical bending mode [Reprinted with permission from Riggs et al. (2007)] 
simulations of a floating offshore wind turbine. The deformation modes of the substructure were added as generalised modes and solved by linear potential flow around the floating structure. In another study by Campos et al. (2017), structural response of an SPAR buoy was analysed with a 3D finiteelement method. Other examples for hydroelasticity analysis of FOWTs can be found in Luan et al. (2017), Aubault et al. (2006), Chen and Mills (2005). The accuracy of the elastic response computed by the modal approach depends on the number of the dry modes.

\section{Coupling of wind, waves, and current loads and structural responses}

A floating wind structure consists of wind turbine(s), a floating platform, and mooring lines. The coupling of the wind, waves, and current loads on these parts, along with the motion and elastic responses of the whole system is a complex problem. The dynamic response of the floating substructure is influenced by both aerodynamic and hydrodynamic loads. The motion of the floating platform results in the motion of the wind turbines. Thus, the relative wind impact experienced by the blades is influenced by the motion of the platform motion and possibly elastic deformations which affect the wind turbine performance. To design a safe, efficient, and cost-effective floating wind turbine, a reliable analysis method is required to take into account the coupling of the wind, wave, and current loads and the structural responses, simultaneously.

The analysis methods developed to determine coupled loads and responses of an FOWT can be classified into two main categories:(i) One-way coupled and (ii) Two-way coupled (fully coupled) tools. These approaches are discussed in the following sections. This is followed by an illustration of the most common computational tools developed for this purpose.

\subsection{Fully coupled approaches}

In a fully (two-way) coupled approach, the fluids (water and air) governing equations and the structural equations are solved simultaneously. The fluid dynamics can be determined by use of several approaches discussed in Sect. 3. To obtain the elastic responses, a structural analysis approach, for instance FEM, can be used to determine the stresses and deformations of the body. The structure equations are solved simultaneously with the fluid equations.

It is possible to obtain a fully coupled response of FOWTs by use of CFD methods where dynamic interactions of the fluids and the structure are solved simultaneously. Due to the high computational demand in this approach, however, so far such studies are limited to rigid bodies and subject to

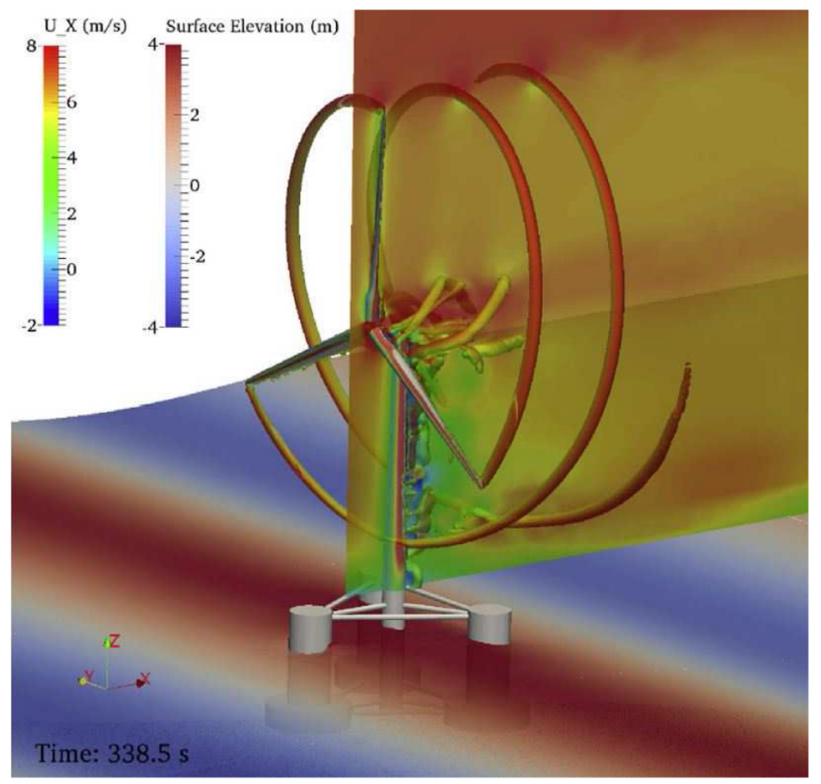

Fig. 8 Fully coupled analysis of an FOWT by CFD. Vortex contour coloured by velocity component $U_{x}$ and colours on the free surface indicate surface elevation [Reprinted with permission from Liu et al. (2017a)]

restricted degrees of freedom for a FOWT, see, e.g., Quallen et al. (2014), Nematbakhsh et al. (2015), Tran and Kim (2016), Cheng et al. (2019). For instance, in a recent study by Liu et al. (2017b), a fully coupled dynamic analysis was performed for a semi-submersible floating wind turbine by use of an open source CFD software, namely OpenFOAM. As shown in Fig. 8, the water and air motions are solved by Navier-Stokes equations and the structural responses are neglected. In addition, Liu et al. (2017b) assumed that the motion of the structure is restricted to surge, heave, and pitch. In this work, the mesh motion and the body movements are modelled by built-in sliding mesh technique.

\subsection{One-way coupled approaches}

Simultaneous solution of the hydrodynamic and aerodynamic loads and responses of FOWTs creates a challenging problem for the state-of-the-art approaches. It is possible to separate (or decouple) these loads and responses from each other, calculate each of the loads independent of others, and then determine the responses of the structure. This approximation obviously simplifies the solution approach and may introduce some errors. The magnitude of errors varies with the time step and the motion of the structure. The computational tools developed based on one-way coupled methods are an extension of the numerical tools originally developed for onshore wind turbines or floating platforms of the $\mathrm{O}$ and $\mathrm{G}$ industry. Additional computational modules are added to 
each of these tools to account for the complete response of FOWTs, see Matha et al. (2016).

In a common approach in one-way coupled analysis of FOWTs, first the translational and rotational motions of the floating structure are obtained by use of the linear diffraction theory. The new position and orientation of the structure is then fed into an aerodynamic analysis module, and then wind loads are estimated. This may result in a change of the position and orientation of the structure. Elasticity of the structure, if considered, is determined at this step using the hydrodynamic and aerodynamic loads. The above procedure is carried out in each time step. In this approach, it is assumed that the platform experiences small oscillations; otherwise, for large motions, the computational error increases. Some typical one-way coupled computational tools for analysis of FOWTs are introduced below.

One-way coupled approaches can be carried out in both time and frequency domains. Some preliminary studies on FOWTs have been performed in frequency domain, see, e.g., Withee (2004), Lee (2005), Wayman et al. (2006), all considering rigid bodies with linearised aerodynamic forces on the turbine. Matha et al. (2009) performed a comparison between the frequency-domain and time-domain analysis on a TLP and recommended the use of time-domain analysis to achieve more accurate coupling between flexible components of wind turbines and the platform motion. Nonetheless, there is an ongoing research on linearised frequency-domain solvers for FOWTs, for instance by Pegalajar-Jurado et al. (2018).

OpenFAST Jonkman and Sclavounos (2006) developed a computational tool named FAST (Fatigue, Aerodynamic, Structures and Turbulence) for dynamic analysis of onshore or offshore, bottom fixed, or floating wind turbines. The most recent version, namely OpenFAST, is developed for modelling the system couplings, the environmental loads, and dynamics of the system under both normal and extreme loadings, see Jonkman et al. (2018).

The aerodynamic loads are calculated via a subroutine called AeroDyn using a quasi-steady BEM theory including the axial and tangential loads. Some empirical corrections, for instance for the tip and hub losses, are included in the subroutine. HydroDyn module computes the hydrodynamic loads with first- and second-order potential flow, strip theory or a combination of both. For potential-flow solution, typical solvers are applied to determine the hydrodynamic coefficients, for instance WAMIT (Wave Analysis MIT, Lee and Newman 1987) and HYDRAN (Riggs et al. 2007). By use of the hydrodynamic coefficients determined by a potential-flow solver, HydroDyn module (Jonkman et al. 2015) computes the linear hydrodynamic loads on the floater in time domain. The viscous effects are estimated and maybe added by use of Morison's equation. The hydrodynamic analysis in OpenFAST is based on small-amplitude motions of

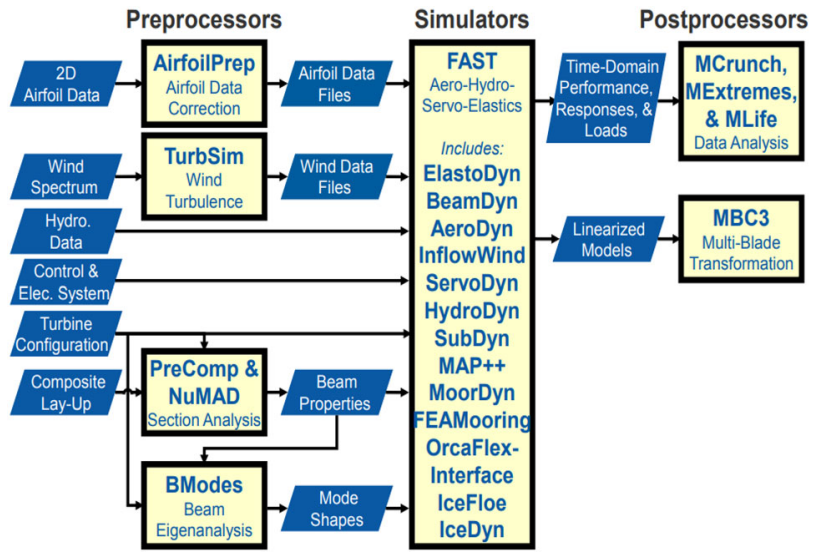

Fig. 9 Flowchart of the dynamic response analysis of a FOWT as followed by OpenFAST [Reprinted with permission from Jonkman and Jonkman (2016)]

the structure. The mooring line analysis is accomplished in $\mathrm{MAP}++$ module. In this module, the mooring lines are modelled statically, where only mean forces on the mooring lines are considered, see Masciola (2016) for more details on the $\mathrm{MAP}++$ module. The inertia forces and fluid drag loads on the mooring lines are not considered. In this solver, the apparent weight, elastic stretching of the mooring lines, and the effect of seabed friction on the anchors are considered. The aeroelastic response is determined in ElastoDyn module, and it is used as the new position of the structure for the following time step. The flowchart of this numerical tool is illustrated in Fig. 9.

OpenFAST only accounts for the elasticity of the tower and blades of the wind turbine, and the structural elastic deformations of the floater are not considered. This assumption may result in some significant errors in predicting the natural frequencies and motion of large floating structures. The fatigue analysis of the platform is of great importance which is also affected by the motion of the wind turbine mounted on top of the floater.

Several studies have been performed to account for the inertia and the drag forces on the mooring lines in OpenFAST. For instance, in a study by Masciola et al. (2011), a time-domain finite-element software that simulates the coupled motion of the floating body and the mooring lines, OrcaFlex, is linked with OpenFAST. MoorDyn developed by Hall (2015) uses a lumped-mass approach to discretize the cable dynamics over the length of the mooring line.

SIMA Workbench SIMA workbench is a numerical tool including SIMO module (Simulation of Marine Operation) for time-domain hydrodynamic analysis of offshore structures and RIFLEX module, a finite-element code to determine structural responses of slender marine bodies, see Skaare et al. (2007). SIMO considers the linear and quadratic potential forces on the body as well as Morison's 
equation for slender parts. The aerodynamic calculations are performed by use of BEM considering numerical corrections for stall and wake effects. Elasticity of slender elements (such as mooring lines) is considered and the floating structure is assumed rigid. The coupling of the loads follows the same procedure as the one-way coupled approaches discussed in this section. Several studies have analysed FOWTs using SIMA workbench, see, e.g., Karimirad and Moan (2012), Kvittem et al. (2012), Karimirad and Michailides (2019). In a study by Skaare et al. (2007), SIMO/RIFLEX were coupled with HAWC2 (Horizontal Axis Wind Turbine Code 2nd generation), which slightly modifies the aerodynamic responses.

GL Bladed GL Bladed is a software developed by DNV (DNV-GL 2014) to determine the performance of fixed wind turbines and their dynamic responses. The aerodynamic loads are computed with corrected BEM theory including corrections for tip and hub losses and stall effect. GL Bladed has two options for hydrodynamic analysis, namely Morison's equation for slender bodies and BEM method. The structural model in this tool is based on flexible multi-body dynamic approach. A finite-element approach is used to determine the hydroelasticity of the structure. Mode shapes and frequencies of the support structures are calculated for each flexible body using modal analysis method. In this numerical tool, the motion of the body is limited to small oscillations.

Deeplines This is another example of a one-way coupled numerical tool developed by Le Cunff et al. (2013) to analyse FOWTs. Deeplines obtains the hydrodynamic frequency-domain coefficients and aerodynamic loads separately from various computational tools. Deeplines is a nonlinear finite-element solver suitable mainly for slender bodies, e.g., blades, tower, mooring lines, and umbilical. The beam element formulation accounts for coupled axial, bending, and torsion effects. Drag term of Morison's equation is combined with potential-flow theory in hydrodynamic analysis. Aerodynamic loads are determined with BEM, where some corrections are added considering turbulent and skewed wake, tower, and stall effects.

Other one-way coupled numerical approaches In a study carried out by Salehyar et al. (2017), a threedimensional unsteady boundary-element model based on the free vortex lattice method is applied to simulate the effects of wind on rotating blades. The total aerodynamic potential consists of three parts, namely the incoming wind, the diffracted potential, and the wake potential. The wake potential is obtained by simplifying the vorticity downwind as infinitely thin distributions of dipoles on the wake panels. BEM is used to solve the air flow governing equations. Similar to OpenFAST, the hydrodynamic loads are obtained separately by use of linear potential solver. This study is restricted to rigid bodies, i.e., the hydroelastic and aeroelastic responses are not considered.

OpenFAST and AeroDyn subroutine are linked with other numerical tools, e.g., CHARM3D and TimeFloat to build another computational tool, see Shim and Kim (2008). CHARM3D is a floater-mooring dynamic analysis program based on FEM method developed by Shim and Kim (2008). Later, the same numerical tool was applied by Bae and Kim (2014) to analyse the dynamic response of multiple wind turbines mounted on a single floater. At each time step, effect of the wind turbines on the floater is considered by introducing generalised degrees of freedom to the equation of motion of the substructure. Thus, one of the main limitations of this tool is that the aerodynamic interaction of the wind turbines on each other is neglected.

TimeFloat developed by Cermelli et al. (2009) is a coupling tool to study the interaction of the floater and the mooring lines simultaneously. The viscous force is computed by Morison's equation. In this model, the rotor is simplified by a disc subject to the same thrust as would be expected on the rotor. The aerodynamic module in TimeFloat is limited to calculation of the thrust force, and the effect of the rotor vibrations on the motion of the floating body is neglected.

Leble and Barakos (2016a) analysed a 10-MW floating wind turbine, where the hydrodynamic loads were computed by SPH method coupled with an aerodynamic tool, namely Helicopter Multi-Block (HMB3) solver. HMB3 solves the wind flow by use of an LES or DES turbulence models. The motion of the structure is determined by a multi-body model made of rigid bodies connected with friction-less joints. The position and velocities of the rotor are passed to HMB3 to compute the aerodynamic loads.

Dynamic response of an FOWT is simulated in time domain with a computational tool (Loose), by Gao and Sweetman (2018). Loose is a multi-body solver that is based on momentum cloud method (MCM), see Sweetman and Wang (2014). In this method, the FOWT is modelled as a rigid body. Translational and rotational motions are determined using Newton's second law and conservation of angular momentum, respectively. Hydrodynamic loads are computed by Morison's equation and aerodynamic loads are obtained by AeroDyn module. A similar approach is followed by Dai et al. (2018) for a one-way coupled numerical tool for analysis of a FOWT.

\section{Experimental studies on FOWTs}

Dynamic behaviour of FOWTs and simultaneous loads on the structure, control systems, and flexible components of the platform and the wind turbine, create a complex problem for theoretical approaches. Model tests are necessary 
in providing further information about the problem, and as comparison references for the theoretical approaches.

Reynold's similarity law for the aerodynamic effects and Froude's similarity law for the hydrodynamic effects cannot be achieved simultaneously. Hence, same as in the Naval Architecture and $\mathrm{O}$ and $\mathrm{G}$ industries, often Froude's scaling law is used in conducting laboratory experiments of FOWTs, see Goupee et al. (2014) and Martin et al. (2014) for more details on the scaling laws for FOWTs. To achieve similar wind thrust coefficients, however, sometimes, geometry of the model scale of the blades is modified. This approach is known as performance scaling, see Martin et al. (2014)

Among others, Koo et al. (2014) and Goupee et al. (2014) and Nihei et al. (2014) have conducted experiments to study the performance of various floating bodies, namely SPAR, semi-submersible, and TLP platforms for FOWTs. In these studies, it is shown that the Response Amplitude Operators (RAOs) in pitch and yaw are highest for an SPAR FOWT when compared to others. TLP platform, compared with others, has shown the smallest RAOs in pitch and heave.

Projects under International Energy Agency Wind Tasks 23 and 30, namely the Offshore Code Comparison Collaboration (OC3), and Offshore Code Comparison Collaboration Continuation (OC4) were established to verify the modelling tools developed for offshore wind turbines with code-to-code comparison. To evaluate the accuracy of the numerical tools, under Offshore Code Comparison Collaboration Continued with Correlation (OC5) task, laboratory measurements for both floating and fixed bottom systems, in model scales, full-scale and open ocean testing were compared with the computational simulations.

In the following subsections, key contributions of laboratory experiments for each type of the FOWTs are presented.

\subsection{SPAR}

Utsunomiya et al. (2009) conducted laboratory experiments on an SPAR platform focusing on the effect of motion suppression devices. The distribution of the wind load on the rotor is simplified by a constant horizontal force on the tower.

More recently, Duan et al. (2016), Ahn and Shin (2019), Tomasicchio et al. (2018) studied model tests of SPARtype FOWTs under wind and wave loadings. In a study by Duan et al. (2016), the dynamic response of a 1/50 model scale of OC3 SPAR floating was studied. It was shown that $\mathrm{RAO}$ of yaw is highly influenced by the rotor rotation and it increases by the amplitude of the incident random waves. It was observed that the surge and pitch motions are strongly coupled, and the heave motion is independent from surge and pitch.

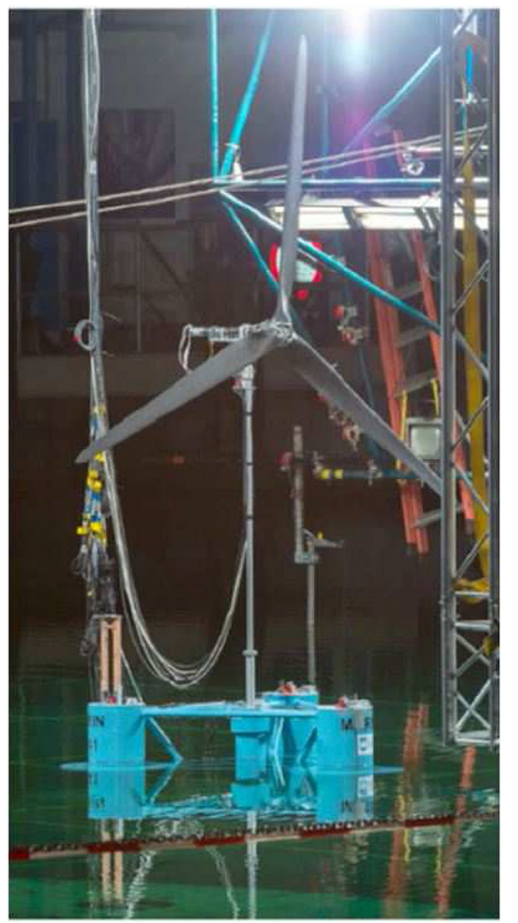

Fig. 10 Instrumented OC5-DeepCwind model in the MARIN offshore basin [Reprinted with permission from Robertson et al. (2017)]

\subsection{Semi-submersible}

At-sea field tests on a 1:8 model of a semi-submersible FOWT, Volturn US, is conducted by Viselli et al. (2014). Important objectives of the field tests include site selection, instrumentation plan, construction methods, and the model responses to the environmental loads. Froude scaling law was used in these tests.

In the second phase of the OC5 project, the DeepCWind semi-submersible was considered. In this study, model tests on the DeepCWind FOWT were conducted at a 1:50 scale, see Robertson et al. 2017. The tests included static offset test, hammer tests, free decay tests, wind-only and wave-only tests, and combination of wind and wave tests. Interaction of wind and waves in the wave basin is another challenge of the experiments. The instrument cables on the structure, shown in Fig. 10, had some effects on the motion of the structure, see, e.g., Coulling et al. (2013b); Robertson et al. (2013). The addition of the instrumentation cables attached to the structure, if not done properly, can result in increased natural frequency and damping of the system in surge, see Matha et al. (2016).

\subsection{TLP}

Oguz et al. (2018), Aoki et al. (2018) among others, conducted laboratory experiments on TLP-type FOWTs. Oguz 




Fig. 11 Model scale of a TLP FOWT at Kelvin Hydrodynamics Laboratory of the University of Strathclyde, UK [Reprinted with permission from Oguz et al. (2018)]

et al. (2018) tested a 1/36.67 scale TLP platform with smallscaled 5-MW NREL wind turbine under regular and irregular wave conditions. The measurements were compared with results of OpenFAST and HydroDyn. It was observed that the numerical tools overestimate the motion responses and the tendon tensions near surge natural period. The displacement of the structure in roll, sway, and yaw was insignificant when compared to surge, pitch, and heave motions.

Conventional pitch-to-feather control systems are used to decrease the thrust force on the rotor of a FOWT at speeds larger that the rated wind speed resulting in large motions of the tower backwards and forwards and it is referred to as negative damping, see Jonkman (2008) for more details. Aoki et al. (2018) studied a 1/100 scale TLP platform with a 5-MW NREL wind turbine, as shown in Fig. 11. The model in this study included the control system to analyse the effect of the negative damping on the motion of the structure. It was observed that negative damping can be dominant in surge motion. It was confirmed that scaling appeared to play a role in these experiments and larger model scales were suggested.

\section{Concluding remarks}

Determining wave, current and wind loads on floating offshore wind turbines and analysing the response of the structure are challenging and critical in design and analysis stages. Simultaneous considerations of the loads and responses are essential for accurate analysis of FOWTs, particularly at extreme cases. In this survey, first an introduction of the state-of the-art approaches to determine the hydrodynamic and aerodynamic loads on FOWTs, as well as the structural responses is presented. Then, a discussion of the coupled numerical tools to analyse the responses of FOWTs is provided.
CFD approaches can be used for a fully coupled fluid (air and water)-structure interaction analysis of FOWTs, potentially of any kind. However, CFD approaches require high computational resources and are not as practical. Thus, simplifications are required to reduce the computational effort. These simplifications, in some cases, are very significant resulting in restricted information about the loads and responses of FOWTs. This review article is aimed to discuss such limitations associated to these coupling tools.

Currently, one-way coupling approaches have received more attention, mainly due to the relative simplicity of their use. One-way coupling approaches determine the loads on the structure and its responses separately. These approaches are developed from the existing tools for onshore wind turbines or $\mathrm{O}$ and $\mathrm{G}$ structures.

In one-way numerical coupling approaches, hydrodynamic responses of the structure are determined independently of the aerodynamic loads. That is, the influence of the wind load is not considered when in determining the hydrodynamic response of the floater. In a common approach, the hydrodynamic frequency-domain coefficients are computed with a potential solver and passed to a time-domain simulator to determine the motion of the floater. The main assumption of one-way coupling approaches is that the motion of the floating structure is small. For severe sea states, however, the numerical errors increase. In most of the one-way coupling tools, the aerodynamic loads are computed by a modified BEM theory which include some corrections to approximate the nonlinearities of the aerodynamic loading. The errors become significantly large in extreme environmental conditions, where displacements and accelerations are large. The one-way coupled tools are more efficient by compromising accuracy.

Comparisons of the responses of fully coupled and oneway coupled approaches with laboratory experiments under mild conditions show relatively good agreement. Yet, performance of the numerical tools in extreme conditions is to be determined.

There is a continuous desire to increase the size of the rotor of FOWTs for larger energy production. Consequently, development of approaches that can consider the structural responses and deformations, including the floating platform, would be essential. To limit the numerical error associated with the decoupling of the loads and responses, a method that considers simultaneously both aerodynamic and hydrodynamic loads on the structure as well as the elastic responses would be highly desirable, of course within the computational limitations.

Acknowledgements This work is partially based on funding from the CBJ Ocean Engineering Corp. of Hong Kong. This funding is gratefully acknowledged. Any findings and opinions contained in this paper are those of the authors and do not necessarily reflect the opinions of the funding company. 
Open Access This article is licensed under a Creative Commons Attribution 4.0 International License, which permits use, sharing, adaptation, distribution and reproduction in any medium or format, as long as you give appropriate credit to the original author(s) and the source, provide a link to the Creative Commons licence, and indicate if changes were made. The images or other third party material in this article are included in the article's Creative Commons licence, unless indicated otherwise in a credit line to the material. If material is not included in the article's Creative Commons licence and your intended use is not permitted by statutory regulation or exceeds the permitted use, you will need to obtain permission directly from the copyright holder. To view a copy of this licence, visit http://creativecomm ons.org/licenses/by/4.0/.

\section{References}

Abedi H, Davidson L, Voutsinas S (2017) Enhancement of free vortex filament method for aerodynamic loads on rotor blades. J Solar Energy Eng 139:1-12

Adam F, Myland T, Dahlhaus F, Großmann J, (2014) Gicon®-TLP for wind turbines - the path of development. In: RENEW 2014, CRC Press, November 24-26, Lisbon, Portugal, pp 651-656

Ahn HJ, Shin H (2019) Model test and numerical simulation of OC3 SPAR type floating offshore wind turbine. Int J Naval Archit Ocean Eng 11:1-10

Aidun CK, Clausen JR (2010) Lattice-boltzmann method for complex flows. Ann Rev Fluid Mech 42:439-472

Aoki M, Srinivasamurthy S, Iijima K, Hara N, Ikoma T, Nihei Y (2018) Experimental investigation of negative damping effects for a TLP type offshore wind turbine. In: Proceedings of the ASME 2018 37th international conference on ocean, offshore and Arctic engineering, June 17-22, Madrid, pp 1-8

Aubault A, Cermelli C, Roddier DG (2006) Structural design of a semi-submersible platform with water-entrapment plates based on a time-domain hydrodynamic algorithm coupled with finiteelements. In: Proceedings of the sixteenth international offshore and polar engineering conference (ISOPE), May 28-June 2, San Francisco, pp 187-194

Aubault A, Roddier DG (2013) Offshore wind energy. In: Rose L (ed) Energy: modern energy storage, conversion, and transmission in the 21 st Century. Nova Science Publishers Inc, New York, United States, Chapter 6, pp 121-144

Bae YH, Kim M (2014) Coupled dynamic analysis of multiple wind turbines on a large single floater. Ocean Eng 92:175-187

Barooni M, Ale Ali N, Ashuri T (2018) An open-source comprehensive numerical model for dynamic response and loads analysis of floating offshore wind turbines. Energy 154:442-454

Benitz MA, Schmidt DP, Lackner MA, Stewart GM, Jonkman JM, Robertson AN (2014) Comparison of hydrodynamic load predictions between reduced order engineering models and computational fluid dynamics for the OC4-DeepCwind semi-submersible. In: Proceedings of the ASME 2014 33rd international conference on ocean, offshore and Arctic engineering, ASME, June 8-13, San Francisco, pp 1-11

Bento N, Fontes M (2019) Emergence of floating offshore wind energy: technology and industry. Renewa Sustain Energy Rev 99:66-82

Bihs H, Kamath A, Lu JZ, Øivind AA (2017) Simulation of floating bodies using a combined immersed boundary with the level set method in REEF3D. In: VII international conference on computational methods in marine engineering, 13-15 May, Nantes, pp 1-11

Bingham HB, Zhang H (2007) On the accuracy of finite-difference solutions for nonlinear water waves. J Eng Math 58:211-228

Bogner S, Rüde U (2013) Simulation of floating bodies with the lattice Boltzmann method. Comput Math Appl 65:901-913
Borg M, Bredmose H, Hansen AM (2017) Elastic deformations of floaters for offshore wind turbines: Dynamic modelling and sectional load calculations. In: Proceedings of the ASME 2017 36th international conference on ocean, offshore and Arctic engineering, ASME, June 25-30, Trondheim, pp 1-10

Bose ST, Park GI (2018) Wall-modeled large-eddy simulation for complex turbulent flows. Ann Rev Fluid Mech 50:535-561

Butterfield S, Musial W, Jonkman J, Sclavounos PD (2005) Engineering challenges for floating offshore wind turbines. In: Offshore Wind Conference, Oct 26-28, Copenhagen, pp 1-13

Campos A, Molins C, Trubat P, Alarcón D (2017) A 3D FEM model for floating wind turbines support structures. Energy Procedia 137:177-185

Carbon Trust (2015) Floating offshore wind: market and technology review. Technical Report, the scottish government, pp 1-168

Cermelli C, Roddier GD, Aubault A (2009) Windfloat: a floating foundation for offshore wind turbines-part II: hydrodynamics analysis. In: Proceedings of the ASME 2009 28th international conference on ocean, offshore and Arctic engineering, ASME, May 31-June 5, Honolulu, pp 135-143

Chan GKY, Sclavounos PD, Jonkman J, Hayman G (2015) Computation of nonlinear hydrodynamic loads on floating wind turbines using fluid-impulse theory. In: Proceedings of the ASME 2015 34th international conference on ocean, offshore and Arctic engineering, ASME, May 31-June 5, St. John's, Newfoundland, pp 1-9

Chen Cy, Mills T (2005) A review of in-place design approaches for SPAR hulls. In: Proceedings of the ASME 2005 24th international conference on offshore mechanics and Arctic engineering, ASME, June 12-17, Halkidiki, pp 831-840

Chen Xj Wu, Ys Cui Wc, Jensen JJ (2006) Review of hydroelasticity theories for global response of marine structures. Ocean Eng 33:439-457

Cheng P, Huang Y, Wan D (2019) A numerical model for fully coupled aero-hydrodynamic analysis of floating offshore wind turbine. Ocean Eng 173:183-196

Cordle A, Jonkman JM (2011) State of the art in floating wind turbine design tools. Renew Energy 8:367-374

Coulling AJ, Goupee AJ, Robertson AN, Jonkman JM, (2013a) Importance of second-order diffraction forces in the validation of a fast semi-submersible floating wind turbine model. In: Proceedings of the ASME 2013 32nd international conference on ocean, offshore and Arctic engineering, June 9-14, Nantes, pp 1-10

Coulling AJ, Goupee AJ, Robertson AN, Jonkman JM, Dagher HJ (2013) Validation of a fast semi-submersible floating wind turbine numerical model with DeepCwind test data. J Renew Sustain Energy 5:1-28

Craddon L, Weywada PL, Atcheston M, (2016) The offshore environment. In: Cruz, J. and Atcheston M (Eds), Floating offshore wind energy, The next generation of wind energy. Springer, Switzerland. chapter 2, pp 21-85

Dai J, Hu W, Yang X, Yang S (2018) Modeling and investigation of load and motion characteristics of offshore floating wind turbines. Ocean Eng 159:187-200

DNV-GL (2014) BLADED-wind turbine design software. Technical Report, DNV-GL

Du Z, Selig M (1998) A 3D stall-delay model for horizontal axis wind turbine performance prediction. In (1998) ASME wind energy symposium, American institute of aeronautics and astronautics, Jan 12-15, Reston, Virigina, pp 427-448

Du Z, Selig M (2000) The effect of rotation on the boundary layer of a wind turbine blade. Renew Energy 20:167-181

Duan F, Hu Z, Niedzwecki JM (2016) Model test investigation of a SPAR floating wind turbine. Marine Struct 49:76-96

Ducrozet G, Bingham HB, Engsig-Karup AP, Ferrant P (2010) Highorder finite difference solution for 3D nonlinear wave-structure interaction. J Hydrodyn Ser B 22:225-230 
Engsig-Karup AP, Bingham HB, Lindberg O (2008) An efficient flexible-order model for 3D nonlinear water waves. J Comput Phys 228:2100-2118

Ertekin RC, Kim JW (1999) Hydroelastic response of a floating mattype structure in oblique, shallow-water waves. J Ship Res 43:241254

Ertekin RC, Riggs HR, Che XL, Du SX (1993) Efficient methods for hydroelastic analysis of very large floating structures. J Ship Res 37:58-76

Ertekin RC, Webster WC, Wehausen JV (1986) Waves caused by a moving disturbance in a shallow channel of finite width. J Fluid Mech 169:275-292

Faltinsen OM (1990) Wave loads on offshore structures. Ann Rev Fluid Mech 22:35-56

Fang Y, Duan L, Han Z, Zhao Y, Yang H (2020) Numerical analysis of aerodynamic performance of a floating offshore wind turbine under pitch motion. Energy 192:1-17

Gao J, Sweetman B (2018) Design optimization of hull size for SPARbased floating offshore wind turbines. J Ocean Eng Marine Energy 4:217-229

Gingold RA, Monaghan JJ (1977) Smoothed particle hydrodynamics: theory and application to non-spherical stars. Month Not R Astron Soc 181:375-389

Glauert H (1963) Airplane Propellers. Springer, London

Global Wind Energy Council (2018) GWEC global wind 2017 report. A snapshot of top wind markets in 2017: offshore wind. Technical Report

Göçmen T, Laan PVD, Réthoré PE, Diaz AP, Larsen GC, Ott S (2016) Wind turbine wake models developed at the technical university of denmark: a review. Renew Sustain Energy Rev 60:752-769

Gomez-Gesteira M, Rogers BD, Dalrymple RA, Crespo AJC (2010) State-of-the-art of classical SPH for free-surface flows. J Hydraul Res 48:6-27

Goupee AJ, Koo BJ, Kimball RW, Lambrakos KF, Dagher HJ (2014) Experimental comparison of three floating wind turbine concepts. J Offshore Mech Arctic Eng 136:1-9

Green AE, Naghdi PM (1974) On the theory of water waves. Proc R Soc Lond Ser A Math Phys Sci 338:43-55

Green AE, Naghdi PM (1976a) A derivation of equations for wave propagation in water of variable depth. J Fluid Mech 78:237-246

Green AE, Naghdi PM (1976b) Directed fluid sheets. Proc R Soc Lond Ser A Math Phys Sci 347:447-473

Guma G, Bangga G, Jost E, Lutz T, Krämer E (2018) Consistent 3D CFD and BEM simulations of a research turbine considering rotational augmentation. J Phys Conf Ser 1037:1-10

Hall M (2015) MoorDyn user's guide. Department of Mechanical Engineering, University of Maine. Orono, Technical report

Hansen MOL, Sørensen JN, Voutsinas S, Sørensen N, Madsen HA (2006) State of the art in wind turbine aerodynamics and aeroelasticity. Prog Aerosp Sci 42:285-330

Hansen MOL (2007) Aerodynamics of Wind Turbines, 2nd edn. Earthscan Publications Ltd, London, Sterling, VA

Hayatdavoodi M, Ertekin RC (2015a) Wave forces on a submerged horizontal plate. part I: theory and modelling. J Fluids Struct 54:566-579

Hayatdavoodi M, Ertekin RC (2015b) Wave forces on a submerged horizontal plate. part II: solitary and cnoidal waves. J Fluids Struct 54:580-596

Hayatdavoodi M, Neill DR, Ertekin RC (2018) Diffraction of cnoidal waves by vertical cylinders in shallow water. Theor Comput Fluid Dyn 32:561-591

Hayatdavoodi M, Treichel K, Ertekin RC (2019) Parametric study of nonlinear wave loads on submerged decks in shallow water. J Fluids Struct 86:266-289
Henderson A, Collu M, Masciola MD (2016) Overview of floating offshore wind technology. In: Cruz J, Atcheston, M (eds) Floating offshore wind energy, Springer, Switzerland. chapter 3, pp 87-123

Ishihara T, Phuc PV, Sukegawa H, Shimada K, Ohyama T (2007) A study on the dynamic response of a semi-submersible floating offshore wind turbine system part 1: a water tank test. In: Proceedings of the 12th international conference on wind engineering, July 1-6, Cairns, pp 2511-2518

Ishihara T, Zhang S (2019) Prediction of dynamic response of semisubmersible floating offshore wind turbine using augmented Morison's equation with frequency dependent hydrodynamic coefficients. Renew Energy 131:1186-1207

Jeon M, Lee S, Lee S (2014) Unsteady aerodynamics of offshore floating wind turbines in platform pitching motion using vortex lattice method. Renew Energy 65:207-212

Jiao J, Ren H, Chen C (2017) Model testing for ship hydroelasticity: a review and future trends. J Shanghai Jiaotong Univ (Sci) 22:641650

Jonkman BJ, Jonkman JM (2016) FAST v.8.16 Manual. Technical Report. National renewable energy laboratory, national wind technology center. Accessed Mar 2018

Jonkman JM (2008) Influence of control on the pitch damping of a floating wind turbine. In: 46th AIAA aerospace sciences meeting and exhibit, Americal institute of aeronautics and astronautics, Jan 7-10, Reno, Nevada, USA, pp 1-15

Jonkman JM, Robertson AN, Hayman GJ (2015) HydroDyn user's guide and theory manual. Technical Report, national renewable energy laboratory. Accessed Mar 2018

Jonkman JM, Sclavounos PD (2006) Development of fully coupled aeroelastic and hydrodynamic models for offshore wind turbines. In: (2006) ASME wind energy symposium, Jan 13-17. National Harbor, Maryland, USA, pp 1-24

Jonkman JM, Wright AD, Hayman GJ, Robertson AN (2018) Fullsystem linearization for floating offshore wind turbines in OpenFAST. In: Proceedings of the ASME 2018 1st international offshore wind technical conference, Nov 4-7, San Francisco, USA, pp $1-10$

Karimirad M, Michailides C (2015) V-shaped semi-submersible offshore wind turbine: an alternative concept for offshore wind technology. Renew Energy 83:126-143

Karimirad M, Michailides C (2019) Fault condition effects on the dynamic response of $\mathrm{v}$-shaped offshore wind turbine. J Marine Sci Technol (Jpn) 24:34-45

Karimirad M, Moan T (2012) A simplified method for coupled analysis of floating offshore wind turbines. Marine Struct 27:45-63

Keseric NN (2014) Norway's Solution: hywind-world's first full scale floating turbine. Technical Report, Equinor

Kim H, Lee S, Lee S (2010) Numerical analysis on the aerodynamics of HAWTs using nonlinear vortex strength correction. Curr Appl Phys 10:311-315

Kleefsman K, Fekken G, Veldman A, Iwanowski B, Buchner B (2005) A volume-of-fluid based simulation method for wave impact problems. J Comput Phys 206:363-393

Koo BJ, Goupee AJ, Kimball RW, Lambrakos KF (2014) Model tests for a floating wind turbine on three different floaters. J Offshore Mech Arctic Eng 136:1-11

Kvittem MI, Bachynski EE, Moan T (2012) Effects of hydrodynamic modelling in fully coupled simulations of a semi-submersible wind turbine. Energy Procedia 24:351-362

Lamas-Pardo M, Iglesias G, Carral L (2015) A review of very large floating structures (VLFS) for coastal and offshore uses. Ocean Eng 109:677-690

Lamei A, Hayatdavoodi M, Wong C, Tang B (2019) On motion and hydroelastic analysis of an offshore floating wind turbine. In: Proceedings of the ASME 2018 38th international conference on 
ocean, offshore and Arctic engineering, June 9-14, Glasgow, UK, ASME, pp 1-10

Le Cunff C, Heurtier Jm, Piriou L, Berhault C, Perdrizet T, Teixeira D, Ferrer G, Gilloteaux JC (2013) Fully coupled floating wind turbine simulator based on nonlinear finite element method: part Imethodology. ASME 2013 32nd, American society of mechanical engineers, June 9-14. Nantes, France, pp 1-10

Leble V, Barakos GN (2016a) A coupled floating offshore wind turbine analysis with high-fidelity methods. Energy Procedia 94:523-530

Leble V, Barakos GN (2016b) Demonstration of a coupled floating offshore wind turbine analysis with high-fidelity methods. J Fluids Struct 62:272-293

Lee H, Lee DJ (2019) Numerical investigation of the aerodynamics and wake structures of horizontal axis wind turbines by using nonlinear vortex lattice method. Renew Energy 132:1121-1133

Lee CH, Newman JN (1987) WAMIT User Manual. Technical Report, Massachusetts Institute of Technology (MIT)

Lee JW, Lee JS, Han JH, Shin HK (2012) Aeroelastic analysis of wind turbine blades based on modified strip theory. J Wind Eng Ind Aerody 110:62-69

Lee KH (2005) Responses of floating wind turbines to wind and wave excitation. Master of Science, Department of Ocean Engineering, Massachusetts Institute of Technology

Leishman JG (2002) Challenges in modelling the unsteady aerodynamics of wind turbines. Wind Energy 5:85-132

Li B, Fleming CA (1997) A three dimensional multigrid model for fully nonlinear water waves. Coast Eng 30:235-258

Li S, Lamei A, Hayatdavoodi M, Wong C (2019) Concept design and analysis of wind-tracing floating offshore wind turbines. In: Proceedings of the ASME 2019 2nd International Offshore Wind Technical Conference, November 3-6, St. Julian's, Malta, ASME, pp 1-8

Li Y, Paik KJ, Xing T, Carrica PM (2012) Dynamic overset CFD simulations of wind turbine aerodynamics. Renew Energy 37:285-298

Liu MB, Liu GR (2010) Smoothed particle hydrodynamics (SPH): an overview and recent developments. Arch Comput Methods Eng $17: 25-76$

Liu X, Lu C, Liang S, Godbole A, Chen Y (2017a) Vibration-induced aerodynamic loads on large horizontal axis wind turbine blades. Appl Energy 185:1109-1119

Liu Y, Li S, Yi Q, Chen D (2016) Developments in semi-submersible floating foundations supporting wind turbines: a comprehensive review. Renew Sustain Energy Rev 60:433-449

Liu Y, Xiao Q, Incecik A, Peyrard C, Wan D (2017b) Establishing a fully coupled CFD analysis tool for floating offshore wind turbines. Renew Energy 112:280-301

Liu Y, Yoshida S, Hu C, Sueyoshi M, Sun L, Gao J, Cong P, He G (2018) A reliable open-source package for performance evaluation of floating renewable energy systems in coastal and offshore regions. Energy Convers Manag 174:516-536

Lu D, Fu S, Zhang X, Guo F, Gao Y (2019) A method to estimate the hydroelastic behaviour of VLFS based on multi-rigid-body dynamics and beam bending. Ships Offshore Struct 14:354-362

Luan C, Gao Z, Moan T (2017) Development and verification of a timedomain approach for determining forces and moments in structural components of floaters with an application to floating wind turbines. Marine Struct 51:87-109

MacPhee D, Beyene A (2013) Fluid-structure interaction of a morphing symmetrical wind turbine blade subjected to variable load. Int J Energy Res 37:69-79

Manwell J, McGowan J, Rogers A (2002) Wind Energy Explained, vol 2. Wiley, Chichester

Marten D, Lennie M, Pechlivanoglou G, Nayeri CN, Paschereit CO (2015) Implementation, optimization and validation of a nonlinear lifting line free vortex wake module within the wind turbine simulation code QBLADE. Proc ASME Turbo Expo 9:1-10
Martin HR, Kimball RW, Viselli AM, Goupee AJ (2014) Methodology for wind/wave basin testing of floating offshore wind turbines. J Offshore Mech Arctic Eng 136:1-9

Masciola MD (2016) The MAP ++ theory and user manual. Technical Report, NREL. https://nwtc.nrel.gov/MAP. Accessed Dec 2019

Masciola MD, Robertson AN, Jonkman JM (2011) Investigation of a FAST-OrcaFlex coupling module for integrating turbine and mooring dynamics of offshore floating wind turbines. In: International conference on offshore wind energy and ocean energy, Beijing, China, pp 1-10

Matha D, Cruz J, Masciola MD, Bachynski EE, Atcheson M, Groupee Andrew J, Gueydon Sebastien M, Robertson AN (2016) Modelling of floating offshore wind technology. In: Cruz J, Atcheston M (eds) Floating offshore wind energy, the next generation of wind energy, vol 1. Springer, pp 133-240

Matha D, Fischer T, Kuhn M, Jonkman JM (2009) Model development and loads analysis of a wind turbine on a floating offshore tension leg platform. In: European offshore wind conference and exhibition, Stockholm, Sweden, pp 1-6, March 16-19

Matha D, Schlipf M, Cordle A, Pereira R, Jonkman JM (2011) Challenges in simulation of aerodynamics, hydrodynamics, and mooring-line dynamics of floating offshore wind turbines. In: Proceedings of the twenty-first international offshore and polar engineering conference (ISOPE), June 19-24 , Maui, Hawaii, USA, pp 421-428

Melo DB, Baltazar J, Falcão de Campos JA (2018) A numerical wake alignment method for horizontal axis wind turbines with the lifting line theory. J Wind Eng Ind Aerodyn 174:382-390

Mikkelsen RF (2003) Actuator Disc Methods Applied to Wind Turbines. Phd thesis. Technical University of Denmark

Mittal A, Sreenivas K, Taylor LK, Hereth L, Hilbert CB (2016) Bladeresolved simulations of a model wind turbine: effect of temporal convergence. Wind Energy 19:1761-1783

Mo W, Li D, Wang X, Zhong C (2015) Aeroelastic coupling analysis of the flexible blade of a wind turbine. Energy 89:1001-1009

Moin P, Mahesh K (1998) Direct numerical simulation: a tool in turbulence research. Ann Rev Fluid Mech 30:539-578

Morino L (1993) Boundary integral equations in aerodynamics. Appl Mech Rev 46:455-466

Morison J, Johnson J, Schaaf S (1950) The force exerted by surface waves on piles. J Petrol Tech 2:149-154

Musial W, Butterfield S, Boone A (2004) Feasibility of floating platform systems for wind turbines. In: 23rd ASME Wind Energy Symposium, January 5-8, Reno, pp 476-486

Neill DR, Hayatdavoodi M, Ertekin RC (2018) On solitary wave diffraction by multiple, in-line vertical cylinders. Nonlinear Dyn 91:975-994

Nematbakhsh A, Bachynski EE, Gao Z, Moan T (2015) Comparison of wave load effects on a TLP wind turbine by using computational fluid dynamics and potential flow theory approaches. Appl Ocean Res 53:142-154

Newman JN (1978) Marine Hydrodynamics, 40th edn. The MIT Press, Cambridge, London, England

Nihei Y, Iijima K, Murai M, Ikoma T (2014) A comparative study of motion performance of four different FOWT designs in combined wind and wave loads. In: ASME 2014 33rd international conference on ocean, offshore and Arctic engineering, ASME, June 8-13, San Francisco, USA, pp 1-10

Nihei Y, Matsuura M, Fujioka H, Suzuki H (2011) An approach for the optimum design of TLP type offshore wind turbines. In: Proceedings of the ASME 2011 30th International Conference on Ocean, Offshore and Arctic Engineering, ASME, June 19-24, Rotterdam, The Netherlands, pp. 219-227

Oguz E, Clelland D, Day AH, Incecik A, López JA, Sánchez G, Almeria GG (2018) Experimental and numerical analysis of a TLP floating offshore wind turbine. Ocean Eng 147:591-605 
Panahi R, Jahanbakhsh E, Seif MS (2006) Development of a voffractional step solver for floating body motion simulation. Appl Ocean Res 28:171-181

Pegalajar-Jurado A, Borg M, Bredmose H (2018) An efficient frequency-domain model for quick load analysis of floating offshore wind turbines. Wind Energy Sci 3:693-712

Qiu YX, Wang XD, Kang S, Zhao M, Liang JY (2014) Predictions of unsteady HAWT aerodynamics in yawing and pitching using the free vortex method. Renew Energy 70:93-106

Quallen S, Xing T, Carrica P, Li Y, Xu J (2014) CFD simulation of a floating offshore wind turbine system using a quasi-static crowfoot mooring-line model. J Ocean Wind Energy 1:143-152

Rafiee R, Tahani M, Moradi M (2016) Simulation of aeroelastic behavior in a composite wind turbine blade. J Wind Eng Ind Aerodyn 151:60-69

Ramachandran GKV (2012) A numerical model for a floating TLP wind turbine. PhD thesis. Department of Wind Energy, Technical University of Denmark

Rashidi S, Hayatdavoodi M, Esfahani JA (2016) Vortex shedding suppression and wake control: a review. Ocean Eng 126:57-80

Riggs HR, Niimi KM, Huang LL (2007) Two benchmark problems for three-dimensional, linear hydroelasticity. J Offshore Mech Arctic Eng 129:149-157

Riggs HR, Suzuki H, Ertekin RC, Kim JW, Iijima K (2008) Comparison of hydroelastic computer codes based on the ISSC VLFS benchmark. Ocean Eng 35:589-597

Robertson AN, Jonkman JM, Goupee AJ, Coulling AJ, Prowell I, Browning J, Masciola MD, Molta P (2013) Summary of conclusions and recommendations drawn from the DeepCwind scaled floating offshore wind system test campaign. In: Proceedings of the ASME 2013 32nd international conference on ocean, offshore and Arctic engineering, ASME, June 9-14, Nantes, France, pp $1-13$

Robertson AN, Wendt F, Jonkman JM, Popko W, Dagher H, Gueydon S, Qvist J, Vittori F, Azcona J, Uzunoglu E, Soares CG, Harries R, Yde A, Galinos C, Hermans K, de Vaal JB, Bozonnet P, Bouy L, Bayati I, Bergua R, Galvan J, Mendikoa I, Sanchez CB, Shin H, Oh S, Molins C, Debruyne Y (2017) OC5 project phase II: validation of global loads of the deepcwind floating semi-submersible wind turbine. Energy Procedia 137:38-57

Rodriguez SN, Jaworski JW (2019) Strongly-coupled aeroelastic freevortex wake framework for floating offshore wind turbine rotors. part 1: Numerical framework. Renew Energy 141:1127-1145

Salehyar S, Li Y, Zhu Q (2017) Fully-coupled time-domain simulations of the response of a floating wind turbine to non-periodic disturbances. Renew Energy 111:214-226

Sayeed T, Colbourne B, Quinton B, Molyneux D, Peng H, Spencer D (2017) A review of iceberg and bergy bit hydrodynamic interaction with offshore structures. Cold Reg Sci Technol 135:34-50

Sclavounos PD, Lee S, DiPietro J (2010) Floating offshore wind turbines: tension leg platform and taught leg buoy concepts supporting 3-5 MW wind turbines. In: European wind energy conference (EWEC), April 20-23, Warsaw, Poland, pp 1-7

Sebastian T, Lackner M (2010) A comparison of first-order aerodynamic analysis methods for floating wind turbines. In: 48th AIAA aerospace sciences meeting including the new horizons forum and aerospace exposition, American institute of aeronautics and astronautics, Jan 4-7, Reston, Virginia, USA, pp 1-10

Sebastian T, Lackner M (2012a) Analysis of the induction and wake evolution of an offshore floating wind turbine. Energies 5:9681000

Sebastian T, Lackner M (2012b) Development of a free vortex wakemethod code for offshore floating wind turbines. Renew Energy 46:269-275
Sedaghatizadeh N, Arjomandi M, Kelso R, Cazzolato B, Ghayesh MH (2018) Modelling of wind turbine wake using large eddy simulation. Renew Energy 115:1166-1176

Shadloo MS, Oger G, Le Touzé D (2016) Smoothed particle hydrodynamics method for fluid flows, towards industrial applications: Motivations, current state, and challenges. Comput Fluids 136:1134

Shao YL, Faltinsen OM (2014) A harmonic polynomial cell (HPC) method for 3D Laplace equation with application in marine hydrodynamics. J Comput Phys 274:312-332

Shim S, Kim M (2008) Rotor-floater-tether coupled dynamic analysis of offshore floating wind turbines. In: Proceedings of the eighteenth international offshore and polar engineering conference (ISOPE), July 6-11, Vancouver, BC, Canada, pp 455-460

Skaare B, David Hanson T, Nielsen F, Yttervik R, Melchior Hansen A, Thomsen K, Larsen T (2007) Integrated dynamic analysis of floating offshore wind turbines. In: European wind energy conference and exhibition, 7-10 May, Milan, Italy, pp 1-12

Sørensen JN (2011) Aerodynamic aspects of wind energy conversion. Ann Rev Fluid Mech 43:427-448

Sørensen JN, Mikkelsen RF, Henningson DS, Ivanell S, Sarmast S, Andersen SJ (2015) Simulation of wind turbine wakes using the actuator line technique. Philos Trans R Soc 373:1-16

Spalart PR (2009) Detached-eddy simulation. Ann Rev Fluid Mech 41:181-202

Suzuki H, Riggs HR, Fujikubo M, Shugar TA, Seto H, Yasuzawa Y, Bhattacharya B, Hudson DA, Shin H (2007) Very large floating structures. In: Proceedings of the 26th International Conference on Offshore Mechanics and Arctic Engineering, June 10-15, San Diego, pp 1-12

Sweetman B, Wang L (2014) Momentum cloud method for dynamic simulation of rigid body systems. J Eng Mech 140:257-267

Syed Ahmed Kabir IF, Ng EY (2017) Insight into stall delay and computation of 3D sectional aerofoil characteristics of NREL phase VI wind turbine using inverse BEM and improvement in BEM analysis accounting for stall delay dffect. Energy 120:518-536

Tezduyar TE, Sathe S, Schwaab M, Conklin BS (2008) Arterial fluid mechanics modeling with the stabilized space-time fluid-structure interaction technique. Int J Numer Methods Fluids 21:601-629

Thé J, Yu H (2017) A critical review on the simulations of wind turbine aerodynamics focusing on hybrid RANS-LES methods. Energy 138:257-289

Thiagarajan KP, Dagher HJ (2014) A review of floating platform concepts for offshore wind energy generation. J Offshore Mech Arctic Eng 136:1-6

Tomasicchio GR, D’Alessandro F, Avossa AM, Riefolo L, Musci E, Ricciardelli F, Vicinanza D (2018) Experimental modelling of the dynamic behaviour of a SPAR buoy wind turbine. Renew Energy 127:412-432

Tran T, Kim D, Song J (2014) Computational fluid dynamic analysis of a floating offshore wind turbine experiencing platform pitching motion. Energies 7:5011-5026

Tran TT, Kim DH (2016) Fully coupled aero-hydrodynamic analysis of a semi-submersible FOWT using a dynamic fluid body interaction approach. Renew Energy 92:244-261

Tuhkuri J, Polojärvi A (2018) A review of discrete element simulation of ice-structure interaction. Philos Trans R Soc A Math Phys Eng Sci 376:1-16

Utsunomiya T, Sato I, Kobayashi O, Shiraishi T, Harada T (2015) Design and installation of a hybrid-SPAR floating wind turbine platform. ASME 2015 34th International Conference on Ocean, Offshore and Arctic Engineering, ASME, May 31-June 5. St. John's, Newfoundland, Canada, pp 1-9

Utsunomiya T, Sato T, Matsukuma H, Yago K (2009) Experimental validation for motion of a SPAR-type floating offshore wind turbine using 1/22.5 scale model. In: ASME 2009 28th international con- 
ference on ocean, offshore and Arctic engineering, ASME, May 31-June 5, Honolulu, Hawaii, USA pp 951-959

Uzunoglu E, Karmakar D, Guedes Soares C (2016) Floating offshore wind platforms, in: Floating Offshore Wind Platforms, Edts. Castro-Santos, L. and Diaz-Casas, V.. Springer. volume 1, pp. 5377

VAISALA (2015) VAISALA: global leader in environmental and industrial measurement wind time series and prospecting tools. Technical Report. VAISALA www.vaisala.com. Accessed Mar 2018

Vermeer LJ, Sørensen JN, Crespo A (2003) Wind turbine wake aerodynamics. Prog Aerosp Sci 39:467-510

Viré A, Xiang J, Piggott M, Cotter C, Pain C (2013) Towards the fullycoupled numerical modelling of floating wind turbines. Energy Procedia 35:43-51

Viselli AM, Goupee AJ, Dagher HJ (2014) Model test of a 1:8 scale floating wind turbine offshore in the gulf of maine. Ocean Renew Energy 137:1-9 (Volume 9A)

Vorpahl F, Schwarze H, Fischer T, Seidel M, Jonkman JM (2013) Offshore wind turbine environment, loads, simulation, and design. Wiley Interdiscip Rev Energy Environ 2:548-570

Wang CM, Utsunomiya T, Wee SC, Choo YS (2010) Research on floating wind turbines: a literature survey. IES J Part A Civil Struct Eng 3:267-277

Wang L, Liu X, Kolios A (2016) State of the art in the aeroelasticity of wind turbine blades, aeroelastic modelling. Renew Sustain Energy Rev 64:195-210

Wang D, Riggs HR, Ertekin RC (1991) Three-dimensional hydroelastic response of a very large floating structure. Int J Offsh Pol Eng $1: 307-316$

Waters L, Spry W (2019) Section 6-UK Renewables April to June 2019. Technical Report June. Department for Business, Energy and Industrial Strategy, https://www.gov.uk. UK

Wayman EN, Sclavounos PD, Butterfield S, Jonkman JM, Musial W (2006) Coupled dynamic modeling of floating wind turbine systems. In: offshore technology conference, 1-4 May, Houston, Texas, Canada, pp 1-25

Webster WC, Zhao BB (2018) The development of a high-accuracy, broadband, Green-Naghdi model for steep, deep-water ocean waves. J Ocean Eng Marine Energy 4:273-291

Wind Europe (2018) Offshore wind in Europe offshore wind in Europe. Technical Report, wind Europe. Accessed Mar 2018

Withee JE (2004) Fully Coupled Dynamic Analysis of a Floating Wind Turbine System. Ph.D. thesis. Massachusetts Institute of Technology

Wong C (2015) Wind tracing rotational semi-submerged raft for multi-turbine wind power generation. In: European wind energy association offshore 2015 conference, Mar 10-12, Copenhagen, Denmark, pp 1-10

World Energy Council (2016) World energy resources. World Energy Council, London
Wu Y, Wang D, Riggs HR, Ertekin RC (1993) Composite singularity distribution method with application to hydroelasticity. Mar Struct 6:143-163

Wu GX, Ma QW, Eatock Taylor R (1998) Numerical simulation of sloshing waves in a 3D tank based on a finite element method. Appl Ocean Res 20:337-355

Wu YT, Port e Agel F (2015) Modeling turbine wakes and power losses within a wind farm using LES: an application to the Horns Rev offshore wind farm. Renew Energy 75:945-955

Xia D, Ertekin RC, Kim JW (2008) Fluid-structure interaction between a two-dimensional mat-type VLFS and solitary waves by the Green-Naghdi theory. J Fluids Struct 24:527-540

Yeh MK, Wang CH (2017) Stress analysis of composite wind turbine blade by finite element method. In: 5 th Asia conference on mechanical and materials engineering, June 9-11, Tokyo, Japan, pp 1-4

Yu DO, Kwon OJ (2014) Predicting wind turbine blade loads and aeroelastic response using a coupled CFD-CSD method. Renew Energy 70:184-196

Zhang P, Huang S (2011) Review of aeroelasticity for wind turbine: Current status, research focus and future perspectives. Front Energy 5:419-434

Zhang Y, Deng S, Wang X (2019) RANS and DDES simulations of a horizontal-axis wind turbine under stalled flow condition using OpenFOAM. Energy 167:1155-1163

Zhao BB, Duan WY, Ertekin RC (2014a) Application of higher-level GN theory to some wave transformation problems. Coast Eng 83:177-189

Zhao BB, Ertekin RC, Duan WY, Hayatdavoodi M (2014b) On the steady solitary-wave solution of the Green-Naghdi equations of different levels. Wave Mot 51:1382-1395

Zhao BB, Duan WY, Ertekin RC, Hayatdavoodi M (2015) High-level Green-Naghdi wave models for nonlinear wave transformation in three dimensions. J Ocean Eng Marine Energy 1:121-132

Zhu Q, Wolfgang MJ, Yue DK, Triantafyllou MS (2002) Threedimensional flow structures and vorticity control in fish-like swimming. J Fluid Mech 468:1-28

Publisher's Note Springer Nature remains neutral with regard to jurisdictional claims in published maps and institutional affiliations. 